Coles, Jeffrey L., Lemmon, Michael L. and Meschke, Felix, Structural Models and Endogeneity in Corporate Finance: The Link

Between Managerial Ownership and Corporate Performance (April 14, 2011). Journal of Financial Economics, 103.1:149-168.

Publisher's official version: http://dx.doi.org/10.1016/j.jfineco.2011.04.002. Open Access version: http://kuscholarworks.ku.edu/dspace/.

[This document contains the author's accepted manuscript. For the publisher's version, see the link in the header of this document.]

\title{
Structural Models and Endogeneity in Corporate Finance: The Link Between Managerial Ownership and Corporate Performance
}

\author{
Jeffrey L. Coles \\ Arizona State University (ASU) - Finance Department \\ Michael L. Lemmon \\ University of Utah - Department of Finance \\ Felix Meschke \\ University of Kansas - Finance Area
}

This version: April 14, 2011

\section{Paper citation:}

Jeffrey L. Coles, Michael L. Lemmon, J. Felix Meschke, Structural models and endogeneity in corporate finance: The link between managerial ownership and corporate performance, Journal of Financial Economics, Volume 103, Issue 1, January 2012, Pages 149-168, ISSN 0304-405X, 10.1016/j.jfineco.2011.04.002.

\section{Keywords:}

Corporate governance, Managerial ownership, Executive compensation, Corporate performance, Structural model, Endogeneity

\section{Abstract:}

This paper presents a parsimonious, structural model that isolates primary economic determinants of the level and dispersion of managerial ownership, firm scale, and performance and the empirical associations among them. In particular, variation across firms and through time of estimated productivity parameters for physical assets and managerial input and corresponding variation in optimal compensation contract and firm size combine to deliver the well-known hump-shaped relation between Tobin's $Q$ and managerial ownership. To assess the effectiveness of standard econometric approaches to the endogeneity problem, we apply those remedies to panel data generated from the model. The unfortunate conclusion is that, at least in the ownership-performance context, proxy variables, fixed effects, and instrumental variables do not generally provide reliable solutions to simultaneity bias.

Note: Previously titled "Structural Models and Endogeneity in Corporate FinanceStructural Models and Endogeneity in Corporate Finance: The Link Between Managerial Ownership and Corporate Performance" 
Coles, Jeffrey L., Lemmon, Michael L. and Meschke, Felix, Structural Models and Endogeneity in Corporate Finance: The Link

\title{
Structural Models and Endogeneity in Corporate Finance: The Link between Managerial Ownership and Corporate Performance
}

\author{
JEFFREY L. COLES, MICHAEL L. LEMMON, and J. FELIX MESCHKE*
}

This version: April 14, 2011

JEL Classification: G32, G34, L20

Keywords: Corporate governance; Managerial ownership; Executive compensation; Corporate performance; Structural model; Endogeneity

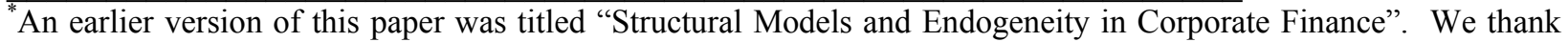
the anonymous referees, Bill Schwert (the editor), Hank Bessembinder, Sanjai Bhagat, Lorenzo Garlappi, Radha Gopalan, Charlie Hadlock, Mike Hertzel, Ohad Kadan, Roni Kisin, Roni Michaeli, Tod Perry, Ed Prescott, Avri Ravid (discussant at EFA 2003), Henri Servaes (discussant at the WFA 2003), Jim Schallheim, and seminar participants at the 2003 Western Finance Association meetings in Los Cabos, the 2003 European Finance Association meetings in Glasgow, Arizona State University, Brigham Young University, Georgia State University, Northwestern University, Purdue University, Vanderbilt University, Texas Christian University, University of Delaware, University of Georgia, University of Illinois, University of Michigan, Washington University in St. Louis, University of Oklahoma, University of Pennsylvania (Wharton), University of Utah, University of Texas, and University of Washington for helpful comments. Albert Wang provided excellent research assistance. Correspondence: Jeffrey Coles, Arizona State University, W.P. Carey School of Business, Department of Finance, P.O. Box 873906, Tempe, AZ, 85287-3906, Tel: 480-965-4475, Jeffrey.Coles@asu.edu. Michael Lemmon is at University of Utah, Tel: 801-585-5210, finmll@business.utah.edu. Felix Meschke is at University of Kansas, Tel: 347-433-5495, meschke@ku.edu.
} 


\begin{abstract}
This paper presents a parsimonious, structural model that isolates primary economic determinants of the level and dispersion of managerial ownership, firm scale, and performance and the empirical associations among them. In particular, variation across firms and through time of estimated productivity parameters for physical assets and managerial input and corresponding variation in optimal compensation contract and firm size combine to deliver the well-known hump-shaped relation between Tobin's $Q$ and managerial ownership. To assess the effectiveness of standard econometric approaches to the endogeneity problem, we apply those remedies to panel data generated from the model. The unfortunate conclusion is that, at least in the ownership-performance context, proxy variables, fixed effects, and instrumental variables do not generally provide reliable solutions to simultaneity bias.
\end{abstract}

JEL Classification: G32, G34, L20 


\section{Structural Models and Endogeneity in Corporate Finance: The Link between Managerial Ownership and Corporate Performance}

\section{Introduction}

This paper pursues two interrelated themes. First, we specify and estimate a structural model of the firm in which managerial contract design, firm size, and firm performance are jointly determined in equilibrium. We use numerical methods to calculate the productivity parameters for managerial input and investment that would give rise to the levels of CEO ownership and investment observed in the data as optimal choices in our model. The structural model is relatively successful in explaining both (a) the level and dispersion of managerial ownership, firm scale, and performance and (b) the character of the empirical associations among those variables. This suggests that our model captures some of the primary economic determinants of the endogenous equilibrium relation between firm performance and structure. Second, we use our model to evaluate a number of commonly applied econometric approaches to the endogeneity problem. Our unfortunate conclusion is that, in the ownership-performance context, the use of proxy variables, fixed effects, and instrumental variables does not generally provide a reliable solution to simultaneity bias. Overall, the construction of our model and its application to data illustrate how quantitative structural models are likely to be applicable to a spectrum of other empirical questions in corporate finance.

For our analysis we focus on a substantial and consistently-active segment of the empirical corporate finance literature, the relation between firm performance and managerial incentives. Important early contributions include Morck, Shleifer, and Vishny (1988), hereafter MSV, which documents a nonmonotonic relation between Tobin's $Q$ and managerial stock ownership, and 
McConnell and Servaes (1990, MS), which reports an "inverted-U” or "hump-shaped" relation between $Q$ and managerial ownership. Numerous successors investigate the ownershipperformance relation using different data, various measures of performance and ownership structure, and alternative empirical methods. ${ }^{1}$

One common interpretation of the estimated hump shape is that the incentive alignment effects of ownership dominate at low ownership levels, but that high ownership levels facilitate managerial entrenchment. ${ }^{2}$ Under this view, shareholders maximize firm value if they can induce managers to own precisely the amount of stock associated with the peak of the performance-ownership relation. In our data the effective ownership from stock and options of the CEO varies from $0.01 \%$ to $57.6 \%$, with a standard deviation of $5.7 \%$, and the point at which the maximum of the estimated hump-shaped relationship between $Q$ and effective CEO ownership is $20.0 \%$. One obvious possibility is that large transaction costs prevent some firms from moving to the optimum. Based on our estimates of the $Q$-ownership relation, however, increasing CEO ownership by one standard deviation, from $14.3 \%$ to $20.0 \%$ implies an increase in firm value equal to $\$ 662$ million on average. Supposing these calculations are representative for the average firm or even just some firms, it seems implausible that the transaction costs of realigning CEO ownership exceed that figure, much less the even greater amounts associated with larger departures of ownership from that which supports maximal $Q$. Based on this line of

\footnotetext{
${ }^{1}$ See Demsetz and Lehn (1985), Kole (1995), Cho (1998), Himmelberg, Hubbard, and Palia (1999), Demsetz and Villalonga (2001), Palia (2001), and Claessens, Djankov, Fan, and Lang (2002), among others. The extent of interest in the performance-ownership relation is documented by Mathiesen (2002), whose dissertation catalogs approximately 100 academic studies on the topic published up through 1999. Also see http://e.viaminvest.com/A5OwnershipStructures/OwPerfStudies/Exhi_1Hypo1to5.asp (accessed April 8, 2011). Many other papers on the topic have appeared since 1999.

${ }^{2}$ See Stulz (1988) for a model containing offsetting costs and benefits of managerial ownership. In that model, firm incentive-alignment effects dominate when inside ownership is low but, as managerial ownership increases, these incentive benefits eventually are overtaken on the margin by the cost of an increased managerial ability to pursue non-value-maximizing activities without being disciplined by shareholders.
} 
reasoning and plausible transaction costs, there is far more variation in observed ownership structure than one would expect.

An alternative interpretation of the data is that the inverted-U pattern represents a valuemaximizing relation between two endogenous variables. Under this view, if the empirical specification adequately captures the effects of all relevant exogenous variables, i.e. those structural parameters that jointly drive both ownership and performance, that specification would be unlikely to detect any remaining relation between the jointly-determined endogenous variables (Demsetz and Lehn, 1985). One challenge for those who operate in the equilibrium paradigm, in this particular empirical context or any other, is to identify the underlying economic forces that drive what presumably is an equilibrium relation between organization structure and firm performance.

We take up this challenge by specifying and estimating a structural model of the firm. Exogenous parameters specify managerial risk aversion, volatility of cash flow, profit margin, productivity of managerial input, productivity of investment, and how cash flow volatility depends on firm size. The shareholders choose investment (firm size) and ownership (the compensation scheme) of the manager, realizing that the manager chooses input, which cannot be observed by the shareholders. Of course, in the standard agency problem (Mirrlees, 1976; Holmström, 1979; and successors) it is the slope of the compensation scheme (i.e., the ex ante sensitivity of managerial wealth to firm performance, or wealth-performance sensitivity (WPS)) that is the primary contractual characteristic that influences the manager's choice of unobservable input. We use data on firm size from Compustat and managerial stock and option ownership from Execucomp to solve for the two model parameters that describe the firm's production function. In particular, for each firm-year observation we calculate the productivity 
parameters for managerial input and investment that would give rise to the observed levels of managerial ownership and total assets as optimal choices in our model. We then use these estimated productivity parameters as variables in the model to generate simulated firm-year data on Tobin's $Q$.

To assess economic content, we confront the model with several classes of empirical tests. From least to most formal, first we find that the model is sufficiently flexible to accommodate what appears in the data. There always exist productivity parameters for investment and managerial input that support observed firm size and CEO ownership as optimal in the model.

Second, relative productivity of managerial input versus investment appears to significantly differ across industries in patterns that might be expected. For example, the relative productivity of managerial input compared to capital is high in personal and business services (including educational services, software development, and networking services) and business equipment (including computers) and low in metal mining and utilities. In the cross-section of industries, CEO ownership is larger and firm size smaller when our measure of productivity of managerial input is high relative to measured productivity of capital.

Third, we examine whether the productivity parameters and our estimate of $Q$ based on the model (call it $Q^{*}$ ) are correlated with actual $Q$ and other operating characteristics of the firm. We find that the correlations between model-generated $Q^{*}$ and $\mathrm{R} \& \mathrm{D}$ intensity, sales, leverage, and advertising effort are statistically significant and have the same sign as the correlations that these variables have with actual $Q$. Additionally, $Q^{*}$ has significant power to explain actual $Q$.

Finally, we directly examine the performance-ownership relation. We find that the simulated data from the model produce the inverted-U relation when we regress model-generated $Q^{*}$ on CEO ownership $(t=9.49)$ and its square $(t=-7.65)$. Based on the estimated coefficients the 
maximal point of the performance ownership relation occurs at $21.2 \%$, which is quite similar to what we obtain (20.0\%) when we estimate the McConnell and Servaes (1990) specification using Execucomp and Compustat data. Overall, the results demonstrate that a simple optimalcontracting model can provide a plausible equilibrium explanation for the nonlinear performance-ownership relation that is widely documented in the literature.

While some readers will view the specification and estimation of the structural model as the chief contribution, others will have a stronger interest in our second research thrust. In particular, we employ the model to evaluate the statistical and economic relevance of the endogeneity problem and whether standard econometric remedies are therapeutic. To begin, we generate a panel of data supposing that our model is the true model and that our estimated exogenous productivity parameters are correct. These productivity parameters are unobservable by the econometrician and within our equilibrium framework, construing them as necessary control variables, their omission in a regression model of $Q$ on ownership leads to a spurious relationship between ownership and firm performance. A standard solution to the omitted variable problem in the literature is to use a variety of control variables as proxies for the unobserved exogenous parameters. Using firm size (e.g., sales), leverage, R\&D expense, advertising expense, and industry indicator variables to proxy for the structural productivity parameters, the spurious relation between $Q$ and managerial ownership typically remains. By way of comparison, adding simple transformations of the actual productivity parameters to the regression yields instead an insignificant relationship between ownership and performance. Together, these results suggest that standard proxy variables are not sufficient to deal with the endogeneity problem in this context and potentially in others as well. Moreover, the model 
reveals that the relation between the unobserved productivity parameters and $Q$ is nonlinear, which also leads to issues arising from misspecification of the functional form.

A second solution to the endogeneity problem is to use panel data and include firm fixedeffects. Fixed effects can accommodate unobserved heterogeneity in the contracting environment. The implicit assumption in the case of firm fixed effects is that the omitted variables that describe the contracting environment are time invariant. In our simulated data the productivity parameters are time-varying and, in this case, we find that firm-fixed effects are insufficient to eliminate the spurious relation between ownership and performance. A third remedy is to use instrumental variables. In our empirical context, we present some evidence on the difficulties of employing the IV approach. Using plausible instruments does not displace the spurious relation between $Q$ and managerial ownership. In the end, our results suggest that endogeneity can be a severe problem and that standard remedies used in the literature often fail, unfortunate conclusions which provide further impetus for application of a structural approach.

In broad terms, our analysis makes three classes of contributions. First, we provide an equilibrium explanation for an important and oft-examined empirical finding. In our framework, the $Q$-ownership relation in the data represents the envelope of value-maximizing contract choice, firm size, and firm performance, all of which are jointly determined based on the exogenous firm-level parameters governing productivity of investment and managerial input. Though our model has a minimal number of elements, it appears to capture some of the essential economic factors that determine contract form, the boundaries of the firm, and firm value, all in a way that is consistent with an important empirical regularity. Second, the methodological implications of our analysis suggest the presence of significant research opportunities in empirical corporate finance. Our model is consistent with recent calls by Zingales (2000) and 
Himmelberg (2002), among others, for a quantitative theory of the firm that is empirically implementable and testable and that allows an assessment of the economic significance of various dimensions of the organization. To this end our work is similar to several other recent papers, including Hennessy and Whited (2005, 2007) and Strebulaev (2007) on capital structure, Riddick and Whited (2009) on corporate cash holdings, and Coles, Lemmon, and Wang (2008) on the joint determinants of compensation policy and board structure.

Finally, our approach can help to avoid the endogeneity and causation problems that commonly plague empirical corporate finance. Doing so is essential. By simulating data from the model, we illustrate the difficulty of controlling for endogeneity and assessing causation using standard methods.

The remainder of the paper is organized as follows. Section 2 presents and analyzes a principal-agent model augmented by an investment (scale) choice. Section 3 describes our sample. Section 4 describes our empirical strategy. In Section 5, we solve the model. Using data on managerial ownership and total assets, we calculate the productivity parameters for managerial input and physical capital that would give rise to observed managerial ownership and firm size as optimal choices in the model. Using the results, we perform numerical comparative statics to characterize the economic importance of changes in the structural parameters for investment, ownership, and our proxy for Tobin's $Q$. Section 6 examines variation across industries in the productivity parameters and $Q^{*}$. We also report the results of our analysis of the correlation between model parameters and firm characteristics. Section 7 shows that our model generates the hump-shaped relation between Tobin's Q and managerial ownership. We also clarify the economic intuition for how the model replicates this important empirical regularity. 
Section 8 examines the severity of the endogeneity problem and assesses the effectiveness of applying the standard econometric remedies. Section 9 concludes.

\section{A Parsimonious Model of Ownership and Investment}

Our model is an adaptation of the Holmström and Milgrom (1987) version of the standard principal-agent problem (Holmström, 1979). In particular, the shareholders, as the collective principal, choose the size of the firm as well as the ownership stake (compensation scheme) of the manager. While it is standard to think of shareholders choosing the managerial compensation scheme, perhaps it is more familiar to think of managers choosing investment. To the extent that investment in physical assets is observable by shareholders, however, it is equivalent to place the decision rights over investment with shareholders.

Firm cash flow is defined by

$$
\tilde{f} \equiv p I^{y} g^{z}+I^{x} \tilde{\varepsilon}
$$

where $I$ is the firm's investment, or assets, and $g$ is the manager's input, such as skill-adjusted effort. Assets $(I)$ can include property, plant, and equipment as well as various intangible assets. Managerial input $(g)$ and investment interact in the production function with parameters $y \in$ $(0,1), z \in(0,1)$, and $z+y \leq 1$ (so as to exclude increasing returns to scale), which determine the productivity of assets and managerial input, respectively. Output is scaled by $p=A p^{+}>0$, where $A>0$ is the standard Cobb-Douglas production function scale factor and $p^{+}$can be interpreted as operating profit margin net of all input costs other than the cost of initial assets and 
the manager's share. ${ }^{3}$ The disturbance term, $I^{x} \tilde{\mathcal{E}}$, is the product of $\tilde{\mathcal{E}} \sim N\left(0, \sigma^{2}\right)$ and a function of investment, $I^{x}$, where $x>0$ is a "curvature" parameter defining how firm size affects cash flow volatility. The disturbance term represents idiosyncratic firm risk, perhaps from a technology shock. Cash flow standard deviation increases with firm size, although perhaps at a decreasing rate $(x<1)$ if some of the risk is diversifiable across the firm's portfolio of different projects.

The manager's utility function is exponential

$$
U(m+\tilde{w}, g)=-e^{[-r(m)(m+\tilde{w}-C(g))]}
$$

where $\tilde{w}$ is the uncertain wage, $m$ is other accumulated managerial wealth, $m+\tilde{w}$ is terminal wealth, $C(g)$ is the money equivalent cost of managerial input, and $r(m)$ is a parameter determining the degree of risk aversion. We focus on the case in which the manager has CARA, so $r(m)=r$, a constant. Nonetheless, our formulation permits risk aversion to depend on $m$ so that later we can test the robustness of our results to using an approximation of CRRA. For algebraic convenience, we let the cost of managerial input be linear, $C(g)=g$, assume $m$ is reservation wealth, and define the manager's reservation utility constraint as $E[U] \geq-e^{-r(m) m}$. Expected utility is

$$
E\left[U(m+\tilde{w}, g)=-e^{\left[-r(m)\left[m+E(\tilde{w})-\frac{r}{2} \sigma^{2}(\tilde{w})-g\right]\right]} .\right.
$$

Following Holmström and Milgrom (1987) (also see Hellwig and Schmidt, 2002), the optimal contract that specifies the manager's claim is linear in the observable outcome: $\phi(\tilde{f})=\tilde{w}=\alpha+\delta \tilde{f}$. Thus, maximizing expected managerial utility in $g$ is equivalent to maximizing

\footnotetext{
${ }^{3}$ Another interpretation of the scale factor within our one-period model is that $p$ also reflects the discount factor for capitalizing future profits. For example, if the margin and profits continue in perpetuity, then $p$ would represent the single-period profit-margin divided by the discount rate.
} 


$$
m+\alpha+\delta p I^{y} g^{z}-\frac{r(m)}{2} \delta^{2} I^{2 x} \sigma^{2}-g
$$

Given the parameters of the contract and initial investment, solving the first-order condition for $g$ yields the manager's optimal input:

$$
g^{*}=\left(z \delta p I^{y}\right)^{\frac{1}{1-z}}
$$

which is increasing in ownership (or slope of the compensation scheme, $\phi^{\prime}(\tilde{f})=\delta$ ), scaled margin, $p$, investment, $I$, and parameters that determine the marginal productivity of managerial input, $z$, and investment, $y .{ }^{4}$ Shareholders maximize expected total surplus

$$
S=E\{[\tilde{f}]-E[\phi(\tilde{f})]-I\}+\left\{E[m+\phi(\tilde{f})]-\frac{r(m)}{2} \delta^{2} I^{2 x} \sigma^{2}-g-m\right\}
$$

subject to the reservation utility constraint that

$$
m+\alpha+\delta E[\tilde{f}]-\frac{r(m)}{2} \delta^{2} I^{2 x} \sigma^{2}-g=m+\alpha+\delta p I^{y} g^{z}-\frac{r(m)}{2} \delta^{2} I^{2 x} \sigma^{2}-g \geq m
$$

the incentive constraint (5), and the requirement for shareholder participation that $S \geq 0$.

For notational convenience we define $n \equiv \frac{z}{1-z}$, with $n \in(0, \infty)$ for $z \in(0,1)$. Substituting optimal managerial input in (6) yields

$$
S=\left(p I^{y}\right)^{n+1}\left(\frac{n}{n+1}\right)^{n} \delta^{n}-I-\frac{r(m)}{2} \delta^{2} I^{2 x} \sigma^{2}-\left(p I^{y}\right)^{n+1}\left(\frac{n}{n+1}\right)^{n+1} \delta^{n+1}
$$

The first-order conditions for the principal's choice of ownership, $\delta$, and assets, $I$, are

$$
\begin{gathered}
\frac{\partial S}{\partial \delta}=\delta\left[-\left(p I^{y}\right)^{n+1}\left(\frac{n}{n+1}\right)^{n+1}(n+1) \delta^{n-1}+n\left(p I^{y}\right)^{n+1}\left(\frac{n}{n+1}\right)^{n} \delta^{n-2}-r(m) I^{2 x} \sigma^{2}\right]=0 \\
\frac{\partial S}{\partial I}=I^{y(n+1)-1}\left(\frac{n}{n+1}\right)^{n} \delta^{n} y^{(n+1)}\left[1-\delta\left(\frac{n}{n+1}\right)\right] p^{n+1}-r(m) x \delta^{2} \sigma^{2} I^{2 x-1}-1=0
\end{gathered}
$$

\footnotetext{
${ }^{4}$ It is simple to show that the second-order condition holds for the agent's choice of input.
} 
Sufficient conditions for any maximum are that the determinants of the principal minors of the matrix of second cross partial derivatives alternate in sign at that critical point. We eliminate all other maxima in favor of the global maximum.

Exogenous parameters are $z$ (or $n), y, x, r(m), \sigma^{2}$, and $p$. Optimal ownership and investment, denoted by $\delta^{*}=\delta^{*}\left(z, y, x, r, \sigma^{2}, p\right)$ and $I^{*}=I^{*}\left(z, y, x, r, \sigma^{2}, p\right)$, arise from solving (9) and (10) and selecting the global maximum. Optimal $\alpha$, denoted by $\alpha^{*}$, is given by substitution in the reservation utility constraint. Despite the simplicity of the model, solving the first-order conditions is non-trivial. ${ }^{5}$ Accordingly, we use numerical methods to solve (9) and (10) and also verify the conditions for the global maximum.

Our single-period model yields a conceptually natural definition for Tobin's $Q$. Modelgenerated $Q^{*}$ equals maximized surplus, $S^{*}$, plus optimal initial investment, $I^{*}$, plus the random shock, all normalized by optimal initial investment, or

$$
Q^{*}=\frac{S^{*}+I^{*}+\left(I^{*}\right)^{x} \tilde{\varepsilon}}{I^{*}}
$$

Firm performance, as measured by $Q^{*}=Q^{*}\left(z, y, x, r, \sigma^{2}, p\right)$, arises endogenously from the production function, the manager's choice of input, value-maximizing choices of effective ownership and size $\left(\left(\delta^{*}=\delta^{*}\left(z, y, x, r, \sigma^{2}, p\right)\right.\right.$ and $\left.I^{*}=I^{*}\left(z, y, x, r, \sigma^{2}, p\right)\right)$, exogenous parameters $\left(z, y, x, r, \sigma^{2}, p\right)$, and the realization of the random disturbance. Clearly, endogenous $Q^{*}, \delta^{*}$, and $I^{*}$ potentially can co-vary as exogenous determinants, $z$ and $y$, vary across firms and through time, but the functional form defining such covariation is far from obvious.

\footnotetext{
${ }^{5}$ It is possible, however, for certain parameter values. For example, if $z=0.5$ (so $n=1$ ), then (9) yields solutions of $\delta=0$ and $\delta=1 /\left(1+\left(2 r(m) \sigma^{2} / p^{2} I^{2(y-x)}\right)\right)$ and the larger solution supports the global maximum. Of course, (9) still needs solving simultaneously with (10) and, in general, analytical solutions are unavailable. For a polynomial of degree $q$ (an integer) $>4$ there is no general algebraic solution. See Conkwright (1941) and Hungerford (1974). Exponents (e.g., in (9) and (10)) that are not integers pose further difficulties.
} 


\section{Sample Collection and Characteristics}

To examine the relation between managerial ownership and firm performance we use data from the Execucomp database covering the years 1993 through 2000. For each firm-year we compute the ex ante sensitivity of $\mathrm{CEO}$ wealth to changes in shareholder wealth. In computing our measure of wealth-performance sensitivity we include the effects of the accumulation of the CEO's direct stock ownership, restricted stock, and existing and newly granted stock options. While WPS is standard terminology in the compensation literature, the derivative of CEO wealth in shareholder value, as defined by $\delta$ in $\varphi(\tilde{f})=\tilde{w}=\alpha+\delta \tilde{f}$, can also quite naturally be interpreted as the effective ownership share of the CEO. Hereafter we use "effective ownership" to refer to $\delta$, otherwise termed WPS.

For direct stock ownership and restricted stock, we use the number of shares of stock held by the CEO divided by the number of shares outstanding. Following Yermack (1995), the portion of effective ownership arising from stock options is the option delta from the Black-Scholes option pricing model (the change in the value of the stock option for a one dollar change in the stock price) multiplied by the ratio of the number of options to total shares outstanding. Following Core and Guay (2002), we compute option deltas separately for new option grants and existing options. For newly granted options, we assume a maturity of seven years, because executive stock options are generally exercised early (e.g., Carpenter, 1998; Huddart and Lang, 1996; and Bizjak, Bettis, and Lemmon, 2005). For existing options, we assume that unexercisable options (i.e., those that are not vested) have a maturity of six years and that exercisable options (i.e., those that are vested) have a maturity of four years. The risk-free rate and volatility estimates for each firm year are given in Execucomp. We compute the effective 
ownership share of the CEO, which corresponds to $\delta^{*}$ in our model, as the sum of the components associated with the CEO's stock ownership, restricted stock, and stock options.

We rely on CRSP and Compustat for other data. To measure firm performance we follow one convention in the literature and use Tobin's $Q$, computed as the book value of total assets minus the book value of equity plus the market value of equity, all divided by total assets. We use data on the book value of total assets and sales as measures of firm size. We use research and development expenditures and advertising expenses, each scaled by total assets, to measure asset intangibility and growth opportunities. ${ }^{6}$ Book leverage is calculated as long-term debt divided by total assets. In some specifications we include either industry dummies for each of the Fama and French 30 industries in the sample or firm fixed effects.

Table 1 reports summary statistics for our sample of 8,570 firm-year observations. The mean effective ownership share of the CEO is 0.033 (median $=0.013$ ) indicating that the CEO's wealth increases 3.3 (1.3) cents for every dollar increase in shareholder wealth. The standard deviation of the CEO's effective ownership share is 0.057 . These values are in line with estimates reported by Murphy (1999) over a similar time period. Book assets of firms in the sample are $\$ 9,649$ million on average and range from a minimum of $\$ 5.88$ million to a maximum of $\$ 902,210$ million (Citigroup in year 2000). ${ }^{7}$ Sales average $\$ 4,268$ million and range from $\$ 0.394$ million to $\$ 206,083$ million (Exxon Mobil in 2000). Leverage averages 0.188 , and the mean values of R\&D and advertising expense scaled by total assets are 0.031 and 0.011 , respectively. Finally, average (median) Tobin's $Q$ for firms in the sample is 2.102 (1.505), the maximum is 45.333, and the minimum is 0.298 .

\footnotetext{
${ }^{6}$ Following Bizjak, Brickley, and Coles (1993), we set missing values of R\&D and advertising expense to zero.

${ }^{7}$ Our sample includes financial firms. Excluding financials does not materially change any of the results reported below.
} 


\section{Solving the Model to Calculate the Exogenous Parameters}

To match the model to data, we use the firm-year observations on firm size (total assets) and the effective ownership share of the CEO, $\delta_{j t}$ and $I_{j t}$, to estimate the productivity parameters for managerial input and investment, $y_{j t}$ and $z_{j t}$, that would give rise to the observed levels of ownership and total assets as optimal choices in our model. In doing so, we assume the observed effective ownership of the CEO and book assets of the firm correspond directly to the same constructs in the model, so

$$
\delta_{j t}=\delta^{*}\left(z_{j t}, y_{j t}, x, r, \sigma^{2}, p\right) \text { and } I_{j t}=I^{*}\left(z_{j t}, y_{j t}, x, r, \sigma^{2}, p\right)
$$

for each firm $j$ and year $t$.

Solving these two equations for the two productivity parameters $z_{j t}$ and $y_{j t}$ requires values for $\left(x, r, \sigma^{2}, p\right)$. The coefficient of absolute risk aversion, $\mathrm{r}=1$, is based on Haubrich (1994), who considers values between 0.125 and 1.125 , and the value for $\sigma=0.333$ is based on the median annualized volatility of monthly stock returns for all firms in our data. Stock return data come from the Center for Research in Security Prices (CRSP). As a proxy for cash flow volatility, $\sigma^{e}$, we use the standard deviation of dollar returns (e.g., Aggarwal and Samwick, 1999) using monthly data on stock returns from CRSP over the 48 months preceding the observation year. We exclude firm-year observations with fewer than 24 months of prior return data. To obtain an estimate of the curvature parameter, $x$, using the cross-section of firms we regress $\ln \left(\sigma^{e}\right)$ on $\ln (I)$, where $I$ is total book assets of the firm. Our point estimate of $x$ is quite close to $x=0.5$, and $x$ reliably falls between 0.4 and 0.6. Recall that $I^{x} \tilde{\mathcal{E}} \sim N\left(0, I^{2 x} \sigma^{2}\right)$. When $x=1.0$ the standard deviation of the shock increases linearly in firm size, and when $x=0.50$ variance 
increases linearly in scale. Based on our estimate, the latter appears to be more realistic. ${ }^{8}$ Nevertheless, we also perform the calculations for $x=0.75$ (and other values as well) so as to gauge the effect of changing the relation between firm scale and volatility. We allow $p$ to differ across industries (Fama and French 30 industries) so as to best match the average level of $Q^{*}$ from the model to the average value of $Q$ in each industry. ${ }^{9}$

Given values for the parameters $\left(x, r, \sigma^{2}, p\right)$, for each firm-year $(j=1,2, \ldots J, ;=1,2, \ldots, T)$ observation in the sample, we use numerical techniques ${ }^{10}$ to solve for the values of $y_{j t}$ and $z_{j t}$ that produce optimal choices of $\delta^{*}$ and $I^{*}$ from the model that match the ownership shares and book assets values in the data, $\delta_{j t}$ and $I_{j t}$. Based on the calculated values of $y_{j t}$ and $z_{j t}$, observed $I^{*}=I_{j t}$, as well as $x$ and simulated cash flow shocks, we also calculate the value of $Q_{j t}$ predicted by the model, $Q_{j t}^{*}$. To simplify notation, generally we suppress the firm-year subscripts hereafter. Recall that model-predicted $Q$ is $Q^{*}=\left(S^{*}+I^{*}+\left(I^{*}\right)^{x} \tilde{\varepsilon}\right) / I^{*}$. To calculate the additive shock, for each firm-year observation we draw a randomly generated value of $\tilde{\varepsilon}$ from $\mathrm{N}\left(0, \sigma^{2}\right)$. We also define $E Q^{*}=\left(S^{*}+I^{*}\right) / I^{*}$ as the value of $Q^{*}$ with the random shock set equal to zero. The approach that we employ to match the model to the data resembles somewhat the methodology used in Baker and Hall (2004) to investigate the relationship between CEO incentives and firm size.

\footnotetext{
${ }^{8}$ The point estimate of $x=0.50$ represents increasing cash flow risk (standard deviation) in size but at a decreasing marginal rate. Perhaps larger firms operate in more lines of business and are more diversified and less risky per dollar invested.

${ }^{9}$ This is the only connection between our empirical procedure and $Q$. If instead we do not allow $\mathrm{p}$ to vary across industries and, for example, set $\mathrm{p}=40$, the results are very similar to those reported below.

${ }^{10} \mathrm{We}$ employ procedure fsolve in the software package Maple to calculate the values of $z$ and $y$ that satisfy (12). In our problem never did we find multiple solutions for $z$ and $y$ when constrained to $0<z, y<1$ and $z+y \leq 1$. The numerical method called in fsolve is Newton-Raphson.
} 


\section{Model Estimates and Comparative Statics}

\subsection{Summary statistics for $Q^{*}, z$, and $y$}

Table 2 presents summary statistics for the estimates of the productivity parameters, $z$ and $y$, and for firm performance, $Q^{*}$. For the base case, where the value of $x$ is 0.5 (Panel A), the mean value of $z$ is 0.0003 , and the median value is 0.00001 . The mean value of $y$ is 0.5613 and the median value is 0.5794 . The mean and median values of $p$ are 55.4 and 40.0 , respectively, and $p$ varies between 5 and 400 across industries. The mean (median) value of $Q^{*}$ produced by the model, 1.94 (1.72), corresponds closely to the actual value of $Q$ in the data. Note that, while our model-generated $Q^{*}$ values include a random disturbance term based on actual cash flow variation, they are still less variable than the actual $Q$ values observed in the data. This is not surprising, since actual $Q$ is likely to be influenced by additional forces outside of our model. Nonetheless, the model is able to match closely the levels of actual $Q$ that appear in the data. Panel B reports the same data for the case where $x$ is 0.75 . Compared to the base case $(x=0.5)$, the mean and median values of $z$ are slightly larger and the values of $p$ are slightly lower.

\subsection{Model comparative statics}

One significant benefit of fitting a structural model to data is the opportunity to gauge the economic significance of the underlying structural parameters as determinants of organization form. In our model, the shareholders choose scale of the firm and the managerial compensation scheme (effective ownership) to maximize value. Exogenous parameters include scaled margin $\left(p=A p^{+}\right)$, risk aversion $(r)$, unscaled standard deviation $(\sigma)$, and the curvature factor for cash flow risk $(x)$. The parameters governing productivity of managerial input $(z)$ and assets $(y)$, estimated as above, also are exogenous in the optimal organization design problem. 
Now consider assessing the sensitivity of model outcomes to changing these parameters, so that the productivity parameters, $z$ and $y$, assume the role of "variables." Table 3 presents estimates of the effect of changing each of these parameters on the optimizing choice of size, effective ownership, and model-generated $Q^{*}$. Because $\delta^{*}$ and $I^{*}$ are nonlinear in the structural parameters (see the first-order conditions, (9) and (10)) and, thus, so is $Q^{*}$, we calculate optimal ownership and size for a benchmark level of the parameter plus and minus a perturbation in that parameter and then calculate the percentage changes in $\delta^{*}, I^{*}$, and $Q^{*}$. We perturb $p, r, \sigma, x, z$, and $y$ by $10 \%$ relative to the benchmark levels. In all calculations, we fix $p=A p^{+}$, for each industry and use $r=1, \sigma=0.33$, and $x=0.50$ as the benchmark levels of the exogenous parameters that do not vary across firms. For the estimated productivity parameters, $z$ and $y$, we use the median values (Table 2, Panel A) as benchmark levels.

Table 3 indicates that a $10 \%$ increase in $z$, which increases the marginal productivity of managerial input, implies a 4.84\% change in the optimal effective ownership level of the CEO, all else equal. An increase in the productivity of managerial input, $z$, has little effect on the level of investment or on $Q^{*}$. A $10 \%$ increase in $y$, which increases the marginal productivity of investment, induces a $4.68 \%$ decrease in the optimal ownership level of the manager and a large $329.19 \%$ increase in firm scale. Within the principal-agent framework of the model, increasing firm size imposes more risk on the manager, all else equal, leading to a decrease in optimal ownership. This effect should be stronger when $x$ is larger because cash flow volatility is more sensitive to scale and compensating the manager for additional risk-bearing is costly. Finally, a $10 \%$ increase in $y$ induces a $9.10 \%$ decrease in on $Q^{*}$. All else equal, an increase in profit margin, $p$, increases the optimal size of the firm, but has negligible effects on ownership and $Q^{*}$. 
Also consistent with the basic intuition of our augmented principal-agent model, increases in managerial risk aversion or volatility have a substantial negative effect on the optimal level of CEO ownership. Increases in risk aversion and volatility, however, have only negligible effects on investment and $Q^{*}$. Increasing $x$, which determines the extent to which scale affects cash flow volatility, decreases ownership but has very little effect on $Q^{*}$ and firm scale. When the values of the parameters are decreased by $10 \%$ from their benchmark levels, the changes in the endogenous variables have opposite sign and are somewhat different in magnitude, reflecting the nonlinearities in the model.

There is another advantage to these comparative statics calculations. In particular, they can be combined with the distribution of the estimated parameters $z$ and $y$ to gain intuition about how the optimizing values of the endogenous variables vary together. This will be particularly useful in Section 7 which discusses the inverted-U relation between $Q$ and managerial ownership.

\section{Comparing the Model to Data}

The prior section shows that there always exist productivity parameters for physical assets and managerial input that support observed firm size and CEO pay-performance sensitivity as optimal. Furthermore, the comparative statics are consistent with the underlying economic intuition of the model. Thus, the model satisfies basic hurdles for validity. In this section, we provide additional evidence regarding the model's ability to conform to real data.

\subsection{Variation across industries}

Table 4 reports median values of the estimated structural parameters, $z$ and $y$, endogenous inside ownership and investment, $\delta^{*}$ and $I^{*}$, and model-generated $Q^{*}$, across industries defined 
following the taxonomy of Fama and French (1997). ${ }^{11}$ A Pearson chi-squared test of goodnessof-fit rejects the null hypothesis that the structural parameters do not vary across industries.

An informal test of our model is whether our estimates of the relative productivity of managerial input versus physical capital appear to vary as one might expect across industries. The data in Panel A of Table 4 are sorted across industries based on the median value of $(z / y) \times$ $10^{4}$ within each industry. The relative importance of managerial input versus physical capital in the production process is highest in Recreation (which includes the movie industry), Personal and Business Services (which includes educational services, software development, and networking services), Healthcare, Restaurants and Hotels, and Business Equipment (including computers). The lowest ratios are in industries such as Precious Metals and Metal Mining, Tobacco Products, Communication, Tobacco, and Utilities (Electric, Gas, and Sanitary Services). Accordingly, managerial ownership is monotonically increasing in the relative productivity of managerial capital to that of investment, while the pattern in firm size is more complex. In absolute terms, physical capital is most productive in Utilities, Steel Works, and Business Supplies, while managerial input is most productive in Recreation, Restaurants and Hotels, and Apparel. Overall, these results are consistent with economic intuition about how the productivity of physical and human capital should vary across industries as a function of the technology.

\subsection{Variation within industry}

We next examine variation within industry. It is quite plausible that steel companies and service companies have different marginal productivity parameters. But does heterogeneity in those parameters really explain variation in size and contract within the steel and service industries? To address this question, Table 4 reports within-industry standard deviations for $z, y$, and $(z / y) \times 10^{4}$. The standard deviation across industries for the average values of $z \times 10^{4}, y$, and

\footnotetext{
${ }^{11}$ Obtained March 3, 2011 from http://mba.tuck.dartmouth.edu/pages/faculty/ken.french/index.html.
} 
$(z / y) \times 10^{4}$ are $2.85,0.11$, and 5.26 , respectively. The average of within-industry standard deviations for $z \times 10^{4}, y$, and $(z / y) \times 10^{4}$ are 13.23, 0.07, and 24.60. The across- and within industry figures are similar for $y$, but variation in $z \times 10^{4}$ and $(z / y) \times 10^{4}$ tends to be much larger within industries than across industries. This suggests that production technology can significantly vary across firms even within the same industry, which is consistent with the large dispersion in firm size and CEO wealth-performance sensitivity within industries observed in the data.

Another interesting question concerning within-industry effects relates to the correlation between extracted parameters $y_{j t}$ and $z_{j t}$. Large firms generally have small $\delta^{*}$, while a small startup firm in the same industry likely would have larger pay-performance sensitivity. Of course, this could be explained by the model if extracted $y$ and $z$ are forced to be negatively correlated within industry. Observe, however, that the structure of the model does not necessarily require this negative correlation in order to fit such data. Larger $y$ implies larger size, $I^{*}$. Larger $I^{*}$ implies larger idiosyncratic cash flow risk, arising from the disturbance $\left(I^{*}\right)^{x} \tilde{\mathcal{E}}$, which implies lower $\delta^{*}$. Thus, the structure of the model does not necessarily require $z$ to be lower when $y$ is higher in order to generate lower $\delta^{*}$. To examine this further, for each industry we calculate the correlation between $z$ and $y$. The average within-industry Pearson correlation is -0.16. This figure is similar to the cross-industry correlation (of industry medians) of -0.12 . Thus, in order to support observed size and CEO wealth-performance sensitivity as optimal choices, the model does not necessarily require a substantially more negative correlation of the productivity parameters within industry versus across industries.

\subsection{Correlations}


Table 5 presents correlations between the productivity parameters and $Q^{*}$ estimated from the model with firm size, ownership, and actual $Q$ from the data. In addition, we present correlations for a number of other control variables, including sales, leverage, $R \& D$ and advertising expenses, that often appear in studies of the relation between ownership and firm performance. Pearson correlations appear below the diagonal and Spearman correlations appear above the diagonal. The Pearson (Spearman) correlation between $z$ and $y$ is $-0.035(-0.555)(\mathrm{p}<$ 0.01). The negative correlation between $z$ and $y$ is consistent with the well-documented negative relation between effective CEO ownership (wealth to performance sensitivity) and firm size (e.g., Bizjak, Brickley, and Coles, 1993; Schaefer, 1996; and Baker and Hall, 2004). In our data, the Pearson (Spearman) correlation between ownership $\left(\delta^{*}\right)$ and total assets is $-0.108(-0.408)(\mathrm{p}$ $<0.01)$. CEOs in larger firms have smaller ownership shares. Within our model, the negative correlation between size and ownership is driven by the fact that idiosyncratic risk (in dollar terms) increases in firm size. ${ }^{12}$

A more direct assessment of our model is to compare the correlations between $Q^{*}$ estimated from the model and $Q$ in the actual data. Recall that the model is estimated to fit the observed values of firm size and ownership that appear in the data, but is not fit to actual $Q$. Thus, any ability of modeled $Q^{*}$ to explain actual $Q$ is not hard-wired. As seen in the Table 5, the Pearson and Spearman correlation coefficients for $Q^{*}$ and $Q$ are $0.342(p<0.01)$ and $0.194(p<0.01)$. Moreover, both actual $Q$ and model-generated $Q^{*}$ are positively correlated with effective ownership $\left(\delta^{*}\right)$ and negatively correlated with total assets $\left(I^{*}\right)$. Finally, both actual $Q$ and model-generated $Q^{*}$ are negatively correlated with sales and leverage and positively correlated with $\mathrm{R} \& \mathrm{D}$ and advertising. Recall that in no way is $Q^{*}$ generated using any information on

\footnotetext{
${ }^{12}$ Again, our model is based on moral hazard, but an alternative would be to focus on adverse selection and sorting of managers (as do Gabaix and Landier, 2008). In our modeling framework, good (high $z$ ) managers could be sorted to productive (high $y$ ) firms, so estimated $z$ and $y$ would be positively correlated in the data. We find the opposite.
} 
sales, leverage, R\&D, or advertising. Thus, the correlations suggest that the form of our model and the fitted structural parameters appear to capture some of the primary economic determinants that drive the relations between firm size, CEO pay-performance sensitivity, and firm performance in the data.

\section{Getting Over the Hump: The Relation between Ownership and Performance}

In this section we examine whether the data generated from the model, in which ownership, firm size, and firm performance, are jointly determined as value maximizing choices can replicate the nonlinear relation between Tobin's $Q$ and ownership $(\delta)$ that has been documented in numerous studies.

\subsection{The link between CEO ownership and firm performance}

Consider the often-reported result of an "inverted-U" or "hump-shaped" relation between ownership and Tobin's $Q$ (e.g., McConnell and Servaes, 1990, and Himmelberg, Hubbard and Palia, 1999). One common interpretation of this finding is that the incentive effects associated with higher ownership are strong for low to medium levels of ownership, but that entrenchment effects dominate at high levels of CEO ownership (Stulz, 1988). This explanation requires substantial costs of adjusting managerial ownership. An alternative possibility is that these results could also arise as the outcome of value-maximizing choices of organizational form driven by underlying exogenous features of the contracting environment. This latter view is the genesis of our principal-agent model, and the question is whether our model can serve to explain the inverted-U shaped relation between ownership and Tobin's $Q$. The answer is yes.

Table 6 reports pooled OLS regressions of Tobin's $Q$ from Compustat data and $Q^{*}$ from our model on the ownership share of the CEO $\left(\delta=\delta^{*}\right)$ and its squared value. Throughout, all test 
statistics are adjusted for heteroscedasticity and clustering within firms (Petersen, 2009). Model 1 in Table 6 reports the results using actual $Q$ as the dependent variable. Consistent with the results reported in many prior studies, our data also reflect the inverse U-shaped relation between Tobin's $Q$ and ownership. The coefficient estimate on the CEO's ownership share is 8.59 (tstatistic $=5.88)$, and the coefficient estimate on the squared ownership of the CEO is $-21.42(\mathrm{t}-$ statistic $=-5.68)$. The ratio of the coefficient estimates of the linear term to that of the squared term is -0.40 , which corresponds to a maximum $Q$ at CEO ownership of $20.00 \%$. The adjusted R-squared of the regression is essentially the same as that reported by Himmelberg, Hubbard, and Palia (1999, Table 5) for the same regression specification.

The remaining columns in Table 6 present results using $Q^{*}$ generated by the model as the dependent variable. We consider two different values of the volatility curvature parameter $(x=$ 0.50, 0.75). Robust t-statistics (Rogers, 1993) are given in brackets. For our base case (Model 2), with $x=0.50$, the coefficient on the ownership share variable is 8.56 (t-statistic $=9.49)$ and the coefficient on the squared ownership share is -20.21 (t-statistic $=-7.65)$. The ratio of the coefficients on the linear term to that on the squared term is -0.42 , which corresponds to a maximum $Q^{*}$ at CEO ownership of $21.19 \%$.

To assess the low standard errors underlying the large t-statistics in Table 6, we implement a bootstrap approach. We resample 10,000 times and report in parentheses the t-statistics based on robust standard errors clustered by gvkey. The t-statistics are quite similar. Bootstrapping the standard errors does not alter inference.

Figure 1 provides a graphical comparison of the results from the model and the results in data. The fitted curve labeled "Actual" is a plot of the predicted values of $Q$ from the regression of $Q$ on effective CEO ownership, $\delta$, per Model 1 of Table 6. The curve labeled " $r=1, x=0.5$ " 
is based on the same regression specification except that model-generated $Q^{*}$ is the "dependent" variable fitted to $\delta$, per Model 2 of Table 6, and then predicted from the parameter estimates and data on $\delta$, The fitted, hump-shaped regression lines are almost indistinguishable. This suggests that our model, with parameters $r=1$ and $x=0.50$, captures economic forces that drive the joint, endogenous relation between Tobin's $Q$ and effective CEO ownership.

Though we focus on $x=0.50$, as estimated from our Execucomp firms, the analogous estimate for all firms on Compustat is 0.75 . Thus, we examine the robustness of the ability of the model to predict the hump to changes in $x$. Model 3 displays the results using $Q^{*}$ generated from estimating the model in our sample with $x=0.75$ as the dependent variable. In this case, the coefficient estimate on the ownership share of the CEO is 7.99 (t-statistic $=8.67$ ). The coefficient estimate on the squared ownership term is $-15.60(\mathrm{t}=-5.53)$. The ratio of the coefficients on the linear term to that on the squared term is -0.51 , which corresponds to a maximum $Q^{*}$ at CEO ownership of $25.62 \%$. The fitted values as a function of $\delta$ are plotted in Figure 1 with label " $r=1, x=0.75$ ". The location and shape are similar to the shapes based on actual Q and on the parameter pair $r=1$ and $x=0.5$.

Is the inverted-U relation independent of exogenous parameters and instead purely a result of the functional forms employed in the model? The answer is no. As Figure 1 indicates, the model is capable of delivering a different relation between $Q^{*}$ and CEO ownership. For example, for $r=1$, setting $x=1$ or larger generates a positively-sloped, convex relation between $Q^{*}$ and effective CEO ownership. On the other hand, for $x=0.75$, even setting $r$ as large as 4 produces a concave relation between $Q^{*}$ and $\delta$. In our model, lower $x$ and lower $r$ tend to favor a concave relation between $Q^{*}$ and CEO ownership. 
This result is important. The model is not hard-wired to deliver the inverted-U relation. Though the inverted-U relation is commonly reported, the literature reports other empirical relations between ownership and $Q$ (see Demsetz and Villalonga, 2001, Figure 1, for a representation of the spectrum of results in the literature). Figure 1 shows that variation in empirical findings across studies of the $Q$-ownership relation could be driven by variation in $x$ or $r$ (or in other characteristics of the contracting environment) across samples and time periods.

\subsection{How the model works}

We now explain how the model gives rise to the observed relation between $Q$ and CEO ownership. Consider an increase in the productivity of physical capital, $y$. As the comparative statics in Table 3 indicate (and as Table 4 suggests) occurs in data, this implies a large increase in investment, a decrease in managerial ownership, and, thus, a decrease in $Q^{*}$. On the other hand, Tables 3 and 4 also show that an increase in productivity of managerial input, $z$, implies an increase in CEO ownership, very little increase in investment (so as to avoid magnifying the exposure of the manager to increased risk), and very little effect on $Q^{*}$. Also recall that the estimated productivity parameters, $z$ and $y$, are negatively correlated in the full sample (Table 5), though the absolute value of that correlation is not particularly large (Pearson correlation = $0.035)$.

Consider first the set of firms for which $z$ and $y$ are negatively correlated. Increasing $z$ and decreasing $y$ will lead to an increase in CEO ownership as the effects of increasing $z$ and decreasing $y$ reinforce each other. In addition, investment (size) declines and $Q *$ increases. For firms represented in this part of the sample, $\delta^{*}$ and $Q^{*}$ will move together. In contrast, consider the subset of sample firms for which $z$ and $y$ increase together. Referring again to Table 3, the overall effect on managerial ownership is ambiguous. Nevertheless, for cases in which $z$ and $y$ 
move together, but where the relative increases in $z$ are larger than those in $y$, optimal ownership $\left(\delta^{*}\right)$ and firm size $\left(I^{*}\right)$, will move together, but $Q^{*}$ will decline, in which case increasing $\delta^{*}$ is associated with decreasing $Q^{*}$.

To reinforce this intuition, Table 7 displays median values of the exogenous productivity parameters, endogenous choice variables, and model-generated $Q^{*}$, all by observed CEO ownership deciles. For deciles one through nine, $y$ falls and $z$ increases. Thus, optimal investment falls relative to optimal CEO ownership and, as a consequence, $Q^{*}$ increases as the importance of managerial input increases relative to that of investment. The top ownership decile contains firms with both high $y$ and high $z$. Thus, as the comparative statics results in Table 3 suggest, while $z, y$, optimal ownership, and CEO input are high, so is investment (at least relative to decile 9), and the negative effect on $Q^{*}$ of higher $y$ and higher investment is larger than the positive effect on $Q^{*}$ of higher $z$ and managerial input. In this way, the structure of the model and distribution of the exogenous productivity parameters in the data combine to yield a hump-shaped, endogenous relation between $Q^{*}$ and managerial ownership.

\subsection{Reduced form representation based on solved parameters}

We now offer two remarks that illuminate further our choice of line of attack.

First, recall that our empirical approach is to solve the equations in (12) for productivity parameters $y$ and $z$ based on observed contract form $\delta$ and firm size $I$ for each firm year. A standard alternative would be to use GMM (e.g.) to estimate fewer productivity parameters using a moment conditions based on the data. For example, one might assume that the productivity parameters are stable for each firm through time or the same for all firms in the same industry.

Note that our solution method can be seen as a special case of that standard approach in which the number of parameters to be estimated is the same as the number of moment conditions 
and all moment conditions are satisfied perfectly. In this context, the discussion in section 7.2 above illustrates some of the reasons for our choice of empirical approach. We view allowing variation of the productivity parameters across firms within an industry as essential given the observed variation of contract form and firm size within industries. Moreover, executives come and go, product markets evolve, and production technologies change, so we also accommodate time-series variation within firms of the solved values for the productivity parameters.

Second, what is the connection between the economic content of our modeling approach and the econometric analysis of the relation between $Q$ and $\delta ?^{13}$ Supposing one could invert the equations in (12) to obtain $\left(y_{j t}, z_{j t}\right)=F\left(\delta_{j t}, I_{j t} \mid r, p, x, \sigma^{2}\right)$, applying the functional form in (11) (call it $\mathrm{G}()$.$) yields Q_{j t}^{*}=G\left(F\left(\delta_{j t}, I_{j t} \mid r, p, x, \sigma^{2}\right)\right) \equiv H\left(\delta_{j t}, I_{j t} \mid r, p, x, \sigma^{2}\right)$. We characterize and analyze these values for $y, z, I=I^{*}, \delta=\delta^{*}$, and $Q^{*}$ in Tables 2-5. In Table 6 , we regress $Q^{*}$ on $\delta^{*}$ and $\left(\delta^{*}\right)^{2}$, which can be written as

$$
H\left(\delta_{j t}, I_{j t} \mid r, p, x, \sigma^{2}\right)=\beta_{0}+\beta_{1} \delta_{j t}+\beta_{2} \delta_{j t}^{2}+u_{j t}
$$

This makes it clear that we are trying to see if the nonlinear relation between $\delta$ and $I$ (and $Q$ ) in the model (the reduced form function $H()$.$) produces the usual hump shape that is found in the$ data. As Table 6 shows, it does.

Note that applying OLS to (13) gives moment restrictions

$$
E\left(u_{j t} \mid 1, \delta_{j t}, \delta_{j t}^{2}\right)=E\left(H\left(\delta_{j t}, I_{j t} \mid r, p, x, \sigma^{2}\right)-\beta_{0}+\beta_{1} \delta_{j t}+\beta_{2} \delta_{j t}^{2} \mid 1, \delta_{j t}, \delta_{j t}^{2}\right)=0, \quad \forall j, t .
$$

One component of the moment restrictions come from the literature (the quadratic in $\delta$ ), while the other comes from our model $(\mathrm{H}()$.$) . In the indirect inference procedure of Gourieroux and$ Monfort (1993, 1996), structural parameters are used to match a simulated reduced-form model to a real-data reduced form model. This would amount to selecting or simulating productivity

\footnotetext{
${ }^{13}$ We thank a referee for suggesting this way of framing our analysis.
} 
parameters to fit the reduced form $\mathrm{H}($.$) (or an imperfect proxy for \mathrm{H}($.$) ) to the known hump as$ given to us in data (e.g., Model 1 in Table 6). We modify this idea insofar as we pick reducedform parameters to match model-generated data to real data, but to different real data. That is, we use other data (on $\delta$ and $I$ ) to solve for the productivity parameters, $y$ and $z$. and then regress the reduced-form result for $Q^{*}$ on $\delta$ and $\delta^{2}$. The conjecture is that our reduced form representation based on solved parameters would generate in a relatively independent (from the exercise of matching productivity parameters to firm size and ownership) fashion the humpshaped relation found in the literature. As Models 2 and 3 in Table 6 indicate, the model succeeds in this respect.

\subsection{Robustness}

\subsubsection{Approximate CRRA}

The primary case we consider is based on CARA utility. To explore whether variation in risk aversion across executives (and firms) changes the ability of the model to explain the data, we also consider an approximation of CRRA utility. Instead of fixing $r=1$, we specify $r(m)=$ $r / m \gamma$, where $m$ represents accumulated wealth of the manager. ${ }^{14}$ In particular, $r=1$ as before and assume $\gamma=0.25$, so that relative risk aversion equals 4, per Haubrich (1994). Because executive wealth associated with the decision problem, $\tilde{w}$, is not included, this is only an approximation of CRRA. On the other hand, the approximation allows us to continue to use our framework with exponential utility and normal cash flow disturbances. To approximate $m$ we rely on Baker and Hall (2004), who assume that CEO wealth is roughly equal to six times salary and bonus. The

\footnotetext{
${ }^{14}$ This procedure is meant to accommodate differences in risk aversion (DARA) depending on wealth. Though our primary intention is to increase the flexibility of the model, note that this procedure also could represent sorting of managers. Our focus is on the agency (moral hazard) problem where contract form is determined by factor productivity (i.e., the investment opportunity set), as represented by $z$ and $y$. But if we were to emphasize adverse selection and sorting of managers, one natural way to do so would be to allow risk aversion to vary in fitting the model. For now, however, our strategy focuses on differences in contract form and firm size being driven by variation in production opportunities rather than by differences in managerial preferences.
} 
elasticity of CEO salary and bonus to firm size in our sample is 0.28 (similar to the 0.30 reported in Murphy, 1999). Because most CEOs have nontrivial accumulated wealth, our empirical approximation is $m_{j t}=\max \left[\$ 5\right.$ million, $\left.6 \times 0.28 \times\left(\text { assets }_{j t}\right)^{2}\right]$, where we rely on Baker and Hall (2004) for the \$5 million minimum. Using the estimates of $r(m)$ computed for each firm-year observation, we again follow the procedure described in Section 3. Numerical techniques extract the values of $y_{j t}$ and $z_{j t}$ that produce optimal choices of $\delta^{*}$ and $I^{*}$ from the model that match the ownership shares and book assets values in the data, $\delta_{j t}$ and $I_{j t}$. We then use the solutions for the productivity parameters to simulate model-predicted $Q^{*}$ for the case of approximate CRRA and re-estimate the regressions in Table 6. The results (available from the authors) are nearly identical to those reported for the CARA case.

\subsubsection{Results based on effective ownership of all named executive officers}

Many studies on ownership and performance use a broader measure of managerial ownership (e.g., the total ownership of all officers and directors reported in the proxy statement). Thus, we repeat the analysis using our ownership measure aggregated over the top executive group as specified in Execucomp. In our sample, top executive ownership averages 0.049 and varies from less than 0.001 to 0.810 . The ownership of top executives is highly correlated with CEO ownership (Pearson correlation $=0.865, \mathrm{p}$-value $<0.01$ ). Repeating the analysis in Table 6 using the broader ownership measure yields results (available from the authors) that are similar to those reported for CEO ownership alone.

\subsubsection{Cross-sectional regression using the time-series averages}

Finally, we examine whether the hump-shaped relation between ownership and $Q$ is primarily driven by within-firm or between-firm variation in the productivity parameters. To do so, we calculate the time-series average of CEO ownership and firm size for each firm in the 
sample and then estimate the model, as before, to obtain a cross-section of parameters, $z$ and $y$, which are used to simulate $Q^{*}$. The data are then used to estimate the regressions like those in Table 6. Again, the results, which come purely from the cross section of firms, are very similar to those we report. Regressing modeled $Q^{*}$ on average ownership yields coefficients on CEO ownership and ownership squared of $8.63(\mathrm{t}$-statistic $=9.93)$ and $-20.67(\mathrm{t}$-statistic $=-6.62)$, respectively (Model 2, Table 6). By way of comparison, regressing the time-series average of actual $Q$ on the time-series average value of ownership and its squared value yields coefficient estimates of $11.38(\mathrm{t}$-statistic $=5.23)$ and $-27.99(\mathrm{t}$-statistic $=-5.21)$, respectively.

This result is reassuring, since one would expect the time-series variation in the contracting environment within a firm to be modest compared to differences across firms.

\section{The Endogeneity Problem}

The analysis presented above illustrates how a parsimonious structural model based on optimizing choices of organizational form can replicate prominent stylized facts that often have been attributed to out-of-equilibrium behavior. In empirical corporate finance in general, many inferences are based on estimated coefficients from reduced-form regressions of either performance on structure or of structure on other structure variables. Structural dimensions of particular interest include managerial compensation, board composition, board size, ownership structure, debt policy, investment policy, dividend policy, leadership structure, antitakeover protections, and product market strategy. Performance measures include accounting profit, stock returns, debt returns, and Tobin's Q.

It is possible that the endogeneity problem in practice has little economic or statistical importance, because either reduced-form OLS regression methods are appropriate or 
implementing the standard econometric antidotes is effective. The alternative, which is less appealing, is that some results are driven by omission of some important aspect of the environment that determines both the dependent and independent variables together, in which case the results reveal little about causation or the underlying structure of the economic problems organizational choices are purported to solve (e.g., Himmelberg, 2002; Hermalin, 2008).

Because we specify and fit a structural model of firm value and managerial ownership to data, we can assess the severity of the endogeneity problem in a controlled experimental context. We assume that the model and productivity parameters are correct and then use the model to generate simulated data, specifically endogenously-determined $Q^{*}$. In essence, we create a data panel for which we know the underlying structural model and appropriate exogenous variables. Regardless of whether one believes our model is the right model, this approach provides a relatively clean framework for evaluating the severity of the endogeneity problem. ${ }^{15}$

In our model the relation between ownership and performance is driven by variation in the productivity parameters, $z_{j t}$ and $y_{j t}$, across firms and across time. In practice, $z$ and $y$ (as well as $p, r, \sigma$, and $x$ ) are not observable to the econometrician, and their omission in the regression analysis leads to a spurious correlation between managerial ownership and firm performance.

\subsection{Proxy variables}

One established approach to this omitted variable problem is to include proxy variables for the unobservable exogenous variables (e.g., Wooldridge, 2001, Ch. 4). Perhaps the most common proxy deployed is some measure of firm size (e.g., Morck, Shleifer, and Vishny, 1988; McConnell and Servaes, 1990; and Himmelberg, Hubbard, and Palia, 1999). Note that in our

\footnotetext{
${ }^{15}$ Our analysis above and in this section has a similar flavor to the approach in Strebulaev (2007). Strebulaev uses a calibrated dynamic trade-off model to simulate capital structure paths and applies standard cross-sectional tests to those data. In Strebulaev (2007) the tests applied to model data are consistent with those reported in the empirical literature. Moreover, the standard interpretation of some test results leads to rejection of the underlying model.
} 
model total assets is endogenously determined. Thus, we use the natural log of sales and its square as an alternative proxy for $y$. Though absent from our analysis, we follow a number of other studies and also include leverage. In our model, an increase in $z$ is associated with an increase in firm assets, a decrease in ownership, and a corresponding decrease in $Q^{*}$. As proxies for $z$, we include the ratio of $\mathrm{R} \& \mathrm{D}$ expense to total assets and the ratio of advertising expense to total assets under the assumption that these variables proxy for the importance of managerial inputs. Finally, because margin, $p$, in our model varies by industry, we include indicator variables for each of the 30 Fama-French industries. If these variables adequately proxy for the unobserved productivity parameters, then the coefficient estimates on the ownership variables in a regression of $Q^{*}$ on ownership and the proxy variables will be statistically insignificant.

Table 8 presents results from regressions of both model $Q^{*}$ and actual $Q$ on CEO ownership, squared CEO ownership, and the proxy and control variables. The primary tests are those with $Q^{*}$ as the dependent variable (Models 1 and 2), but for comparison purposes we also estimate the same specifications with actual $Q$ on the left-hand side (Models 3-5).

In Models 1 and 2 we control for only the firm size variables. Comparing the results of Model 2 to Model 2 in Table 6, including the $\log$ of sales and its square in the regression to “explain" modeled $Q^{*}$ dramatically reduces (by a factor of more than 3 ) the coefficient estimates on the ownership variables. Nonetheless, both the coefficient on CEO ownership and the coefficient on squared ownership remain statistically significant at the 0.01 level. Controlling instead for the log of assets and its square (Model 1) reduces further the coefficient estimates on $\delta$ and $\delta^{2}$ and those estimates also become statistically insignificant. This is not surprising given that $Q^{*}$ and $I^{*}$ are jointly determined by parameters $z$ and $y$. What is surprising, per Model 3, is that the same results holds for the same specification with actual $Q$ as the dependent variable. 
The log of assets and its square seem to be effective instruments for the joint determinants of Tobin's $Q$ and CEO effective ownership.

In contrast, another standard measure of firm size does not perform in like manner. In Model 4 for actual $Q$, as in Model 2 for $Q^{*}$, the $\log$ of sales itself and squared do not usurp the explanatory power of $\delta$ and $\delta^{2}$. Further, supplementing the sales variables with R\&D, advertising, leverage, and industry indicators is ineffective. In Model 5, with actual $Q$ on the left hand side, these additional proxies displace the statistical power of sales but the coefficients on $\delta$ and $\delta^{2}$ remain significant

The results show that the inclusion of standard proxy variables used in the literature to capture the unobserved exogenous variation in the contracting environment that drives both ownership and firm performance need not solve the endogeneity problem. This failure is potentially due to either the fact that the proxy variables are not sufficiently related to the unobserved productivity parameters or that the model suffers from additional misspecification. For example, in the model the relations between the endogenous variables and the exogenous productivity parameters are nonlinear and failure to properly account for this nonlinearity will lead to a misspecification of the functional form. We examine this latter issue in two ways.

First we conduct a RESET test (Wooldridge, 2001, Ch. 6) to test for neglected nonlinearities in Model 2 above. The RESET test adds higher order powers of the fitted values from Model 2 above as additional variables to the regression and then conducts a standard F-test for the joint significance of these additional variables. A rejection indicates that the simple linear model is misspecified. Using squared and cubic powers of the fitted values, the linear specification in Model 2 is rejected at the 0.01 level by the RESET test. 
Second, the data simulated from the model also allow us to address this issue more directly. In particular, the model yields direct estimates of the exogenous productivity parameters that cause the omitted variable problem. Adequately controlling for the omitted variables $y$ and $z$, should drive out the relation between ownership and $Q^{*}$. We repeat the regressions in Table 8 but replace the proxy variables with the solved values of $y$ and $z$. When $Q^{*}$ is the dependent variable, including $y$ and $z$ in the regression, the ownership variables have opposite signs compared to the results reported in Table 6 and both remain statistically significant at the 0.05 level. This result suggests that simple linear controls are not sufficient.

To address this, Model 1 of Table 9 also includes the squared values of the productivity parameters and their inverses. Even with these simple functional forms, both ownership variables become statistically insignificant in this regression. Moreover, this augmented specification explains nearly all of the variation in $Q^{*}\left(\mathrm{R}^{2}>0.99\right)$. Remarkably, per Model 3, the same simple functional forms of the productivity parameters perform similarly when actual $Q$ is the object to be explained. Again, both CEO effective ownership and its square are statistically insignificant.

Finally, in our model, $Q^{*}$ contains all of the information about the productivity parameters that is important for explaining firm performance, including information about the functional form. If our model captures the important economic factors that determine both managerial ownership and $Q$, then using $E Q^{*}$ as an independent variable should drive out any significant relation between ownership and $Q$ in the actual data. Model 4 examines whether or not this is the case. Consistent with this conjecture, the ownership variables become statistically insignificant when $E Q^{*}$ is added as an explanatory variable. 
Overall, these results highlight the importance of specification issues in interpreting the relation between managerial ownership and firm performance using reduced form regressions. In our setting, the specification issues arise both from the unobservability of the underlying exogenous parameters and from the fact that the relationship between Tobin's $Q$ and ownership is driven by a nonlinear function of these exogenous variables. In addition, this analysis provides additional evidence that the underlying economics of the contracting model appear to capture some of the important features of the data.

\subsection{Fixed effects and unobserved firm heterogeneity}

Himmelberg, Hubbard and Palia (1999) suggest using firm fixed effects to control for unobserved heterogeneity in the contracting environment (e.g., differences in the unobserved productivity parameters). The underlying assumption of firm fixed effects is that the unobserved heterogeneity is time invariant. Recall that we estimate the model allowing the productivity parameters to vary both across firms and within firms over time. Thus, including firm fixed effects should not be sufficient to drive out the relation between ownership and $Q^{*}$ unless the within-firm time-series variation of the productivity parameters is sufficiently small.

To examine how the use of fixed-effects performs in our data, Table 10 reports the results for both $Q^{*}$ and actual $Q$, including firm fixed effects to control for the unobserved productivity parameters. Models 1-3 present the results using $Q^{*}$ as the dependent variable and results using actual $Q$ are presented in Models 4-6. In Model 1, we include only the two ownership variables and firm fixed effects. Although the coefficient estimates on the ownership variables are reduced by more than a factor of 3 relative to those reported in Table 6 , both ownership variables retain their signs and remain statistically significant at the 0.05 level. The fact that the ownership variables remain significant is attributable to the within-firm time-series variation in the 
productivity parameters that is not captured by the firm fixed effects. Model 2 adds the proxy variables from Table 8 . If these proxies capture the relevant time-series variation in the unobserved productivity parameters, then their inclusion should eliminate the statistical significance of the ownership variables. This is not the case. The addition of the proxy variables reduces the magnitudes of the coefficients on the ownership variables further, but both remain statistically significant at the 0.05 level (Model 2). Finally, in Model 3, we directly include the estimates of the productivity parameters in place of the proxy variables. In this specification, including the productivity parameters, which vary both in the cross section and through time, eliminates the statistical significance of the ownership variables.

In Models 4-6, we replace $Q^{*}$ with actual $Q$ as the dependent variable. In all of the models, inclusion of firm fixed effects eliminates the statistical significance of the ownership variables. Note however, that in Model 5, where the proxy variables are used as stand-ins for the unobserved productivity parameters, the magnitudes of the coefficients on the ownership variables are similar to those reported in Model 2, but have larger standard errors. This finding is related to the critique by Zhou (2001) who notes that fixed-effects regressions of the relation between managerial ownership and firm performance lack power because they rely purely on time-series variation within firms to identify the relation between ownership and firm performance, and time-series variation in the exogenous parameters that define the contracting environment is likely to be small relative to differences across firms. Consistent with this, the cross-sectional standard deviations of the firm-specific average values of $y$ and $z$ in our sample are 0.14326 and 0.00189 . By way of comparison, the average within-firm standard deviations of $y$ and $z$ are an order of magnitude smaller, 0.01615 and 0.00017 , respectively. 
In the end, although the inclusion of fixed-effects is useful econometrically to control for unobserved heterogeneity in the contracting environment that varies across firms, they do not capture time-variation in the exogenous productivity parameters. Moreover, by obscuring in the cross section what is interesting and important about the contracting and size decisions, firm fixed effects provide little guidance in isolating and quantifying the economic determinants of variation in organization form.

\subsection{Instrumental variables}

The final approach to the endogeneity problem we examine is the use of instrumental variables. While this tactic is appealing in general, finding valid instruments for managerial ownership is likely to be difficult. In particular, Himmelberg, Hubbard, and Palia (1999) argue that, for any variable that plausibly determines the optimal level of ownership, it is likely that the same variable will affect Tobin's $Q$ as well. Even so, they proceed on the presumption that firm size and risk are likely to be correlated with ownership and clean relative to $Q$ and, thus, are suitable instruments for ownership. Of course, in our model, this would be inappropriate -- both firm size $\left(I^{*}\right)$ and risk $\left(=\left(I^{*}\right)^{2 x} \sigma^{2}\right)$ are endogenous, driven primarily by exogenous $y$, and in similar manner the correlation between firm size and $Q^{*}$ is strongly negative (Table 5).

In this challenging empirical context, we use our model to provide some guidance on the use of instrumental variables. In particular, recall that within our model all of the observed variation in managerial ownership is driven by differences in the productivity parameters, $y$ and $z$, both across firms and through time. Moreover, the comparative statics presented in Table 3 suggest that changes in the productivity of managerial input, $z$, have large effects on the optimal level of managerial ownership, but are largely unrelated to $I^{*}$ and $Q^{*}$. In contrast, changes in the productivity of physical assets, $y$, are related to changes in all of optimal ownership, $\delta^{*}$, firm 
size, $I^{*}$, and firm performance, $Q^{*}$ Based on these results, variables that are related to the productivity of managerial input, $z$, but unrelated to the productivity of physical assets, $y$, are likely to be good candidates for instruments. Before proceeding further, it is important to note that in our model using functions of $z$ for $\delta$ is conceptually improper. Both $z$ and $y$ are determinants of $\delta^{*}, I^{*}$, and thus $Q^{*}$. In our model, there is no exogenous source of variation. Nonetheless, the connection between $z$ and $I^{*}$ and $Q^{*}$ is not strong (Table 3), so $\delta^{*}$ predicted from functions of $z$ should satisfy the practical and statistical requirements for a "valid" instrument.

We investigate this more formally. In Table 11, Model 1 presents a regression of managerial ownership on the productivity parameter, $z$, its squared value, and the inverse of $z$. All of the coefficient estimates are statistically significant at the 0.01 level and the R-squared of the regression exceeds $80 \%$, indicating that a significant portion of the variation in effective ownership is driven by differences in the productivity of managerial inputs across firms. Model 2 presents a regression of $Q^{*}$ on the same explanatory variables. As seen from the table, although the coefficient estimates are all statistically significant, the R-squared of the regression is only $0.66 \%$, indicating that the productivity parameter $z$ contains little relevant information regarding firm performance. Thus, predicted $\delta^{*}$ is likely to be a statistically appropriate instrument.

Models 3 and 4 present instrumental variables regressions of $Q^{*}$ on fitted managerial ownership and the fitted value of managerial ownership squared. Predicted ownership is based on Model 1. Predicted ownership squared, based on a regression of managerial ownership squared on the same functions of $z$ (results not reported here), is the other instrument. In Model 3 , the coefficient estimates on the instrumented ownership variables are 3.28 on ownership and - 
8.10 on the squared ownership variable and both are statistically significant at the 0.01 level. Using these instruments reduces the magnitudes of the coefficient estimates on the ownership variables by over one-half compared to Table 6, but, the hump-shaped relation between ownership and performance survives nevertheless, even though $z$ has very little explanatory power for $Q^{*}$. Model 4 extends the analysis by including the productivity parameter, $y$, as well as its square and the inverse of $y$ as additional exogenous variables. In Model 4, the magnitudes of the coefficient estimates on both fitted ownership variables are near zero, but both remain statistically significant at the 0.01 level.

Overall, the results further highlight the difficulties econometricians face in choosing valid instruments. Within our model we know that no causal relation between ownership and $Q^{*}$ exists. Rather, $\delta^{*}$ and $Q^{*}$ are jointly determined by $z$ and $y$. Nevertheless, we illustrate that, even though our proposed instruments are nearly uncorrelated with $Q^{*}$, a spurious correlation between ownership and $Q^{*}$ generally remains. This is especially important since it generally is not possible to test for identification. The assumption that the error term in the original regression and the instrument are uncorrelated is not testable but instead must be maintained.

\section{Conclusion}

This paper specifies a structural model of the firm in which managerial contract design, firm size, and firm performance are jointly determined in equilibrium. We estimate the parameters of the model using data from Execucomp, CRSP and Compustat. Our approach is to calculate the productivity parameters for managerial input and investment that would give rise to the observed levels of CEO ownership and investment as optimal choices in our model. In terms of the economic importance for firm design of the structural productivity parameters, increasing the 
productivity of managerial input has a strong positive effect on the optimal level of managerial ownership, but very little effect on firm scale and model-generated $Q^{*}$. On the other hand, increasing investment productivity has a substantial positive effect on optimal firm scale and a strong negative effect on both the slope of the compensation contract and on $Q^{*}$.

We find that the estimated firm-level productivity parameters vary significantly and in an intuitive fashion across industries. In addition, we find that the estimates of $Q$ obtained from the model $\left(Q^{*}\right)$ are significantly correlated with actual $Q$ in the data. Model-generated $Q^{*}$ is also correlated with scaled R\&D expenditure, sales, leverage, and scaled advertising expenditure in the same way that these variables are correlated with actual $Q$.

We directly examine the relation between managerial ownership and firm performance predicted by our model. The equilibrium relationships between the endogenous variables in our model produce the familiar inverted-U relation when we regress $Q^{*}$ on CEO ownership and its square. While an established interpretation of the hump is based on a tradeoff between incentive alignment and entrenchment effects, our augmented principal-agent model lends credence to the idea that $Q$ and $\delta$ (ownership) vary together endogenously, as their underlying determinants, marginal productivity of investment and input, vary in the cross-section and through time. Thus, our model provides an explanation of the empirical relationship between performance and managerial ownership as an envelope of optimal contract design and the level of $Q^{*}$ arising from maximized firm value. Consistent with the equilibrium interpretation of our model, including simple transformations of the productivity parameters generated by our model on the right-hand side of the regression drives out the relation between ownership and $Q^{*}$. These results suggest that we have isolated at least some of the joint economic determinants of contract design, firm size, and firm performance. 
Finally, we use our model to evaluate a number of commonly applied econometric approaches to the endogeneity problem. Our unfortunate conclusion is that in the ownershipperformance context the use of proxy variables, fixed effects, and instrumental variables does not generally provide a reliable solution to the endogeneity problem. One prominent reason is that nonlinear regression specifications are likely to be appropriate. Another is that some remedies do not address endogeneity arising from the joint time-series (within-firm) variation of performance, size, and contract design.

In addition to providing an explanation for a prominent empirical regularity, the construction of our model and its application to data provide one illustration of how quantitative structural models can be applied to a spectrum of empirical questions in corporate finance. Our procedure provides an example of how a structural model of the firm can isolate the important aspects of governance and quantify the economic significance of incentive mechanisms. Moreover, though we do not do so in this paper, this approach is more likely to permit well-specified tests of competing hypotheses and present the opportunity for conducting analysis of economic policies aimed at changing exogenous aspects of the underlying contracting environment. As Himmelberg (2002) points out, this is a line of attack that has been employed successfully in other branches of economics. Furthermore, our approach is consistent with recent calls by Zingales (2000) and Himmelberg (2002), among others, for a quantitative theory of the firm that is empirically implementable and testable and that allows an assessment of the economic significance of various dimensions of the organization. Finally, our analysis coincides with other recent interest in endogeneity concerns and solutions (e.g., Roberts and Whited, 2011). 


\section{REFERENCES}

Aggarwal, R. ,Samwick, A., 1999. The other side of the trade-off: the impact of risk on executive compensation. Journal of Political Economy 107, 65-105.

Agrawal, A., Knoeber, C., 1996. Firm performance and mechanisms to control agency problems between managers and shareholders. Journal of Financial and Quantitative Analysis 31, 377-97.

Alves, C., Mendes, V., 2002. Corporate governance policy and company performance: The Portuguese case. Unpublished working paper, University of Porto.

Baker, G., Hall, B., 2004. CEO incentives and firm size. Journal of Labor Economics 22, 767798.

Bhagat, S. Jefferis, R., 2002. The Econometrics of Corporate Governance Studies. MIT Press: Cambridge.

Bizjak, J., Brickley, J.,Coles, J., 1993. Stock-based incentive compensation and investment behavior. Journal of Accounting and Economics 16, 349-372.

Bizjak, J., Bettis, J., Lemmon, M., 2005. Exercise behavior, valuation, and the incentive effects of employee stock options. Journal of Financial Economics, 76, 445-470.

Carpenter, J, 1998. The exercise and valuation of executive stock options. Journal of Financial Economics 48, 127-158.

Cho, M-H. 1998. Ownership structure, investment, and the corporate value: an empirical analysis. Journal of Financial Economics 47, 103-121.

Claessens, S., Djankov, S., Fan, J., Lang, L., 2002. Disentangling the incentive and entrenchment effect of large shareholdings. The Journal of Finance, 57, 2741-2771.

Clinch, G. 1991., Employee compensation and firms' research and development activity. Journal of Accounting Research 29, 59-78.

Coles, J., Daniel, N., Naveen, L., 2006. Managerial incentives and risk-taking, Journal of Financial Economics 79, 431-468.

Coles, J., Lemmon, M., Wang, Y., 2008. The joint determinants of managerial ownership, board independence, and firm performance. Unpublished working paper, Arizona State University.

Conkwright, N., 1941. Introduction to the Theory of Equations. Ginn and Company: Boston and New York.

Core, J., Guay, W., 2002a. Estimating the value of employee stock option portfolios and their sensitivities to price and volatility. Journal of Accounting Research 40, 613-630. 
Core, J., Guay, W., 2002b. The other side of the trade-off: The impact of risk on executive compensation a comment. Unpublished working paper, University of Pennsylvania.

Demsetz, H., 1983. The structure of ownership and the theory of the firm. Journal of Law and Economics 26, 375-90.

Demsetz, H., Lehn, K., 1985. The structure of corporate ownership: Causes and consequences. Journal of Political Economy 93, 1155-77.

Demsetz, H., Villalonga, B., 2001. Ownership structure and corporate finance. Journal of Corporate Finance 7, 209-33.

Denis, D., Denis, D., Sarin, A., 1997. Agency problems, equity ownership, and corporate diversification. Journal of Finance 52, 135-60.

Fama, E., French, K., 1997. Industry costs of equity. Journal of Financial Economics 43, 153193.

Gabaix, X., Landier, A., 2008. Why has CEO pay increased so much? The Quarterly Journal of Economics 123, 49-100.

Gaver, J., Gaver, K., 1993. Additional evidence on the association between the investment opportunity set and corporate financing, dividend, and compensation policies. Journal of Accounting and Economics 16, 125-160.

Gouriéroux, C., Monfort, A., Renault, E., 1993. Indirect inference. Journal of Applied Econometrics 8, S85--S118.

Gouriéroux, C., Monfort, A., 1996. Simulation-based econometric methods. Oxford University Press: Oxford, UK.

Haubrich, J., 1994. Risk aversion, performance pay, and the principal-agent problem. Journal of Political Economy 102, 307-343.

Hellerstein, J., Neumark, D., Troske, K., 1999. Wages, productivity, and worker characteristics: Evidence from plant-level production functions and wage equations. Journal of Labor Economics 17, 409-446.

Hellwig, M., Schmidt, K.,2002. Discrete-time approximations of the Holmstrom Milgrom Brownian-motion model of intertemporal incentive provision. Econometrica 70, 2225-2264.

Hennessy, C., Whited, T., 2005. Debt dynamics. Journal of Finance 60, 1129-1165.

Hennessy, C., Whited, T., 2007. How costly is external financing? Evidence from a structural estimation. Journal of Finance 62, 1705-1745. 
Hermalin, B., Weisbach, M., 1988. The determinants of board composition. RAND Journal of Economics 19, 580-606.

Hermalin, B., Weisbach, M., 1991. The effect of board composition and direct incentives on firm performance. Financial Management 21, 101-112.

Hermalin, B., Weisbach, M., 2001. Boards of directors as and endogenously-determined institution: A survey of the economic evidence. Economic Policy Review 9, 7-26.

Himmelberg, C., 2002. Measuring the real effects of corporate governance: A note for the gcgf research meeting, April 5, 2002, Washington, DC. Unpublished working paper, Columbia University.

Himmelberg, C., Hubbard, R., Love, I., 2002. Investor protection, ownership, and the cost of capital. Unpublished working paper, Columbia University.

Himmelberg, C., Hubbard, R., Palia, D., 1999. Understanding the determinants of managerial ownership and the link between ownership and performance. Journal of Financial Economics $53,353-84$.

Holderness, C., Kroszner, R., Sheehan, D., 1999. Were the good old days that good? Changes in managerial stock ownership since the great depression. Journal of Finance 54, 435-469.

Holmstrom, B., 1979. Moral hazard and observability. Bell Journal of Economics 10, 74-91.

Holmstrom, B., Milgrom, P., 1987. Aggregation and linearity in the provision of intertemporal incentives. Econometrica 55, 303-28.

Huddart, S., Lang, M., 1996. Employee stock option exercises: An empirical analysis. Journal of Accounting and Economics 21, 5-43.

Hungerford, T., 1974. Algebra. Holt, Rinehart and Winston: New York.

Kennedy, P., 1992. A Guide to Econometrics. MIT Press: Cambridge.

Koopmans, T., Hood, W., 1953. The estimation of simultaneous linear economic relationships. In T.C. Koopmans and W.C. Hood (eds.). Studies in Econometric Method. John Wiley: New York.

Kydland, F., Prescott, E., 1982. Time to build and aggregate fluctuations. Econometrica 50, $1345-70$.

LaPorta, R., Lopez de Silanes, F., Shleifer, A., Vishny, R., 2002. Investor protection and corporate valuation. Journal of Finance 57, 1147-70. 
Lins, K., 2003. Equity ownership and firm value in emerging markets. Journal of Financial and Quantitative Analysis 38, 159-184.

Loderer, C., Martin, K., 1997. Executive stock ownership and performance: tracking faint traces. Journal of Financial Economics 45, 223-55.

Mathiesen, H., 2002. Managerial ownership and financial performance. Ph.D. Dissertation, Department of International Finance and Economics, Copenhagen Business School.

McConnell, J., Servaes, H., 1990. Additional evidence on equity ownership and corporate value. Journal of Financial Economics 27, 595-612.

McGrattan, E., Prescott, E., 2005. Expensed and sweat equity. Unpublished working paper 636, Federal Reserve Bank of Minneapolis.

Mehran, H., 1995. Executive compensation structure, ownership, and firm performance. Journal of Financial Economics 38, 163-185.

Mirrlees, J., 1976. The optimal structure of incentives and authority within an organization. Bell Journal of Economics 7, 105-131.

Morck, R., Shleifer, A., Vishny, R., 1988. Management ownership and market valuation. Journal of Financial Economics 20, 293-315.

Murphy, K., 1999. Executive compensation. In Ashenfelter, O., Card, D., (eds.). Handbook of Labor Economics, Vol. 3b. Elsevier Science North Holland: Amsterdam.

Odegaard, B., Bohren, O., 2001. Corporate governance and economic performance: A closer look. Unpublished working paper, Norwegian School of Management.

Palia, D., 2001. The endogeneity of managerial compensation in firm valuation: A solution. Review of Financial Studies 14, 735-64.

Petersen, M., 2009. Estimating standard errors in finance panel data sets: comparing approaches. Review of Financial Studies 22, 435-80.

Renneboog, L., Trojanowski, G., 2002. The managerial labour market and the governance role of shareholder control structures in the UK. Unpublished working paper, Tilburg University.

Riddick, L., Whited, T., 2009. The Corporate Propensity to Save. Journal of Finance 64, 17291766.

Roberts, M., Whited, T., 2011. Endogeneity in empirical corporate finance. Unpublished working paper, University of Rochester. 
Coles, Jeffrey L., Lemmon, Michael L. and Meschke, Felix, Structural Models and Endogeneity in Corporate Finance: The Link

Rogers, W., 1993. Regression Standard Errors in Clustered Samples. Stata Technical Bulletin $13,19-23$.

Seifert, B., Gonenc, H., Wright, J., 2002. The international evidence on performance and equity ownership by insiders, blockholders, and institutions. Unpublished working paper, Old Dominion University.

Smith, C., Watts, R., 1992. The investment opportunity set and corporate financing, dividend, and compensation policies. Journal of Financial Economics 32, 263-292.

Strebulaev, I., 2007. Do tests of capital structure theory mean what they say? Journal of Finance $62,1747-1787$.

Stulz, R., 1988. Managerial control of voting rights: Financing policies and the market for corporate control. Journal of Financial Economics 20, 25-54.

White, H., 1980. A heteroscedasticity consistent covariance matrix estimator and a direct test of heteroskedasticity. Econometrica 48, 817-18.

Yermack, D., 1995. Do corporations award ceo stock options effectively? Journal of Financial Economics 39, 237-69.

Zhou, X., 2001. Understanding the determinants of managerial ownership and the link between ownership and performance: comment. Journal of Financial Economics 62, 559-571.

Zingales, L., 2000. In search of new foundations. Journal of Finance 55, 1623-1653. 
Coles, Jeffrey L., Lemmon, Michael L. and Meschke, Felix, Structural Models and Endogeneity in Corporate Finance: The Link

\section{Summary Statistics: Effective CEO Ownership and Firm Characteristics}

This table provides summary statistics for effective CEO ownership and sample firm characteristics. Data come from Execucomp and Compustat and consist of 8570 firm-year observations from 1993 to 2000. T he effective ownership share of the CEO $\left(\delta^{*}\right)$ is computed as the fractional direct stock ownership of the CEO plus the effective fractional ownership arising from the CEO's stock option holdings. Leverage is the ratio of long-term debt to total book assets. Missing values of $\mathrm{R} \& \mathrm{D}$ and advertising expenses are set to zero. Tobin's $Q$ is computed as the book value of assets less the book value of equity plus the market value of equity all divided by the book value of assets.

\begin{tabular}{lrrrrr} 
& Mean & Median & Std. Dev. & Min & Max \\
\hline Effective Ownership Share of CEO $\left(\delta^{*}\right)$ & 0.0328 & 0.0133 & 0.0566 & 0.0001 & 0.5757 \\
Book Assets $\left(I^{*}\right)(\$ M M)$ & 9,649 & 1,375 & 35,515 & 5.8810 & 902,210 \\
Sales (\$MM) & 4,268 & 1,178 & 11,302 & 0.3940 & 206,083 \\
Leverage (Debt) Ratio & 0.1878 & 0.1691 & 0.1577 & 0.0000 & 0.9993 \\
R\&D / Book Assets & 0.0314 & 0.0000 & 0.0764 & 0.0000 & 2.0907 \\
Advertising / Book Assets & 0.0108 & 0.0000 & 0.0360 & 0.0000 & 0.5821 \\
Tobin's $Q$ & 2.1024 & 1.5051 & 2.0426 & 0.2983 & 45.3325 \\
\hline
\end{tabular}




\section{Table 2}

\section{Summary Statistics: Estimated Productivity Parameters and Modeled $Q^{*}$}

This table presents summary statistics for endogenous $Q^{*}$ and exogenous productivity parameters $y, z$, and $p$, all based on the model described in Section 3. For the calculation of $y, z$, and "Modeled Tobin's $Q^{*}(x=0.5)$ " in Panel A, exogenous parameters are $r=1, \sigma=0.333$, and $x=0.5$. For the calculation of "Modeled Tobin's $Q^{*}(x=0.75)$ " in Panel B, $x=0.75$, while all other exogenous parameters remain the same. For comparison, the actual Tobin's $Q$ (from Table 1) is reported in Panel C.

Panel A: Parameters for $\boldsymbol{x}=\mathbf{0 . 5}$

\begin{tabular}{lrrrrr} 
& Mean & Median & Std. Dev. & Min & Max \\
\hline$y(x=0.5)$ & 0.5613 & 0.5794 & 0.1391 & 0.0612 & 0.8664 \\
$z(x=0.5)$ & 0.0003 & 0.00001 & 0.0018 & $\approx 0$ & 0.0525 \\
$p(x=0.5)$ & 55.4356 & 40 & 49.6360 & 5 & 400 \\
Modeled Tobin's $Q^{*}(x=0.5)$ & 1.9435 & 1.7252 & 0.7653 & 1.1556 & 16.5342 \\
\hline
\end{tabular}

Panel B: Parameters for $\boldsymbol{x}=\mathbf{0 . 7 5}$

\begin{tabular}{lrrrrr} 
& Mean & Median & Std. Dev. & Min & Max \\
\hline$y(x=0.75)$ & 0.5597 & 0.5762 & 0.1395 & 0.0617 & 0.8664 \\
$z(x=0.75)$ & 0.0075 & 0.0004 & 0.0309 & $\approx 0$ & 0.4750 \\
$p(x=0.75)$ & 55.1576 & 40 & 49.6636 & 5 & 400 \\
Modeled Tobin's $Q^{*}(x=0.75)$ & 1.9491 & 1.7321 & 0.7729 & 1.0965 & 16.6023 \\
\hline
\end{tabular}

Panel C: Tobin's $Q$ from Compustat

\begin{tabular}{rrrrrr} 
& Mean & Median & Std. Dev. & Min & Max \\
\hline Actual Tobin's $Q$ & 2.1024 & 1.5051 & 2.0426 & 0.2983 & 45.3325 \\
\hline
\end{tabular}




\section{Comparative Statics Results for Ownership, Investment, and Model $Q^{*}$ in Exogenous Parameters}

This table presents comparative statics results for Effective Ownership $\left(\delta^{*}\right)$, Investment $\left(I^{*}\right)$, and Model $E Q^{*}$ in exogenous parameters $z, y, \sigma, r, p$, and $x$ based on the CARA model developed in Sections 2, 3, and 4. The benchmark values for the exogenous parameters are $z=0.00001, y=0.5794, r=1, \sigma=0.333$, and $x=0.5$.

Percent increase for a $10 \%$ increase in parameter

\begin{tabular}{lrrrrrrr} 
& baseline & $\boldsymbol{z}$ & \multicolumn{1}{c}{$\boldsymbol{y}$} & $\boldsymbol{p}$ & \multicolumn{1}{c}{$\boldsymbol{r}$} & \multicolumn{1}{c}{$\boldsymbol{\sigma}$} & \multicolumn{1}{c}{$\boldsymbol{x}$} \\
\hline CEO Ownership $\left(\delta^{*}\right)$ & 0.0124 & 4.838 & -4.677 & 0.000 & -4.677 & -9.032 & -31.452 \\
Investment $\left(I^{*}\right)$ & 1,759 & 0.000 & 329.192 & 25.437 & 0.000 & 0.000 & -0.005 \\
Modeled Tobin's $E Q^{*}$ & 1.726 & 0.000 & -9.096 & -0.006 & 0.000 & -0.006 & -0.006 \\
\hline
\end{tabular}

Percent increase for a $10 \%$ decrease in parameter

\begin{tabular}{lrrrrrrr} 
& baseline & \multicolumn{1}{c}{$\boldsymbol{z}$} & \multicolumn{1}{c}{$\boldsymbol{y}$} & \multicolumn{1}{c}{$\boldsymbol{p}$} & \multicolumn{1}{c}{$\boldsymbol{r}$} & \multicolumn{1}{c}{$\boldsymbol{\sigma}$} & \multicolumn{1}{c}{$\boldsymbol{x}$} \\
\hline CEO Ownership $\left(\delta^{*}\right)$ & 0.0124 & -5.161 & 5.645 & 0.000 & 5.323 & 11.048 & 44.839 \\
Investment $\left(I^{*}\right)$ & 1,759 & 0.000 & -67.533 & -22.158 & 0.002 & 0.000 & 0.009 \\
Modeled Tobin's $E Q^{*}$ & 1.7260 & -0.006 & 11.107 & -0.006 & -0.006 & -0.006 & -0.006 \\
\hline
\end{tabular}




\section{Table 4}

\section{Estimated Parameters and Endogenous Variables by Industry}

This table presents median values for estimated parameters $\left(y, z \times \mathbf{1 0}^{4}\right.$, and $\left.(z / y) \times \mathbf{1 0}^{\mathbf{4}}\right)$ as well as median values and standard deviations for endogenous variables $\left(\delta^{*}\right.$ and assets $\left.I^{*}\right)$ for 30 different industry groups, sorted descending by $(z / y) \times 10^{4}$. $N$ denotes the number of observations in each industry group. Industry groups are based on Ken French's classification available at http://mba.tuck.dartmouth.edu/pages/faculty/ken.french/index.html.

\begin{tabular}{|c|c|c|c|c|c|c|c|c|c|}
\hline \multirow[b]{2}{*}{ Industry Name } & \multicolumn{6}{|c|}{ Median Values } & \multicolumn{3}{|c|}{ Standard Deviation } \\
\hline & $\mathbf{N}$ & $I^{*}$ & $\delta^{*}$ & $y$ & $z \times 10^{4}$ & $(z / y) \times 10^{4}$ & $y$ & $z \times 10^{4}$ & $(z / y) \times 10^{4}$ \\
\hline Recreation & 130 & 1,047 & 0.025 & 0.554 & 0.356 & 0.684 & 0.097 & 10.03 & 18.92 \\
\hline Personal and Business & 639 & 557 & 0.023 & 0.341 & 0.190 & 0.620 & 0.088 & 19.11 & 58.14 \\
\hline Healthcare & 677 & 616 & 0.023 & 0.431 & 0.203 & 0.599 & 0.116 & 5.36 & 15.40 \\
\hline Restaurants & 163 & 467 & 0.022 & 0.597 & 0.336 & 0.528 & 0.066 & 7.68 & 12.79 \\
\hline Business Equipment & 911 & 642 & 0.021 & 0.447 & 0.198 & 0.476 & 0.093 & 10.60 & 21.89 \\
\hline Apparel & 118 & 470 & 0.019 & 0.546 & 0.242 & 0.422 & 0.053 & 19.99 & 34.16 \\
\hline Retail & 540 & 1,102 & 0.018 & 0.557 & 0.193 & 0.356 & 0.071 & 15.93 & 32.40 \\
\hline Textiles & 74 & 924 & 0.017 & 0.756 & 0.236 & 0.309 & 0.022 & 34.32 & 48.81 \\
\hline Transportation & 223 & 1,308 & 0.016 & 0.644 & 0.204 & 0.292 & 0.057 & 47.77 & 75.11 \\
\hline Consumer Goods & 151 & 1,208 & 0.015 & 0.499 & 0.119 & 0.263 & 0.081 & 10.58 & 22.14 \\
\hline Construction & 297 & 998 & 0.015 & 0.633 & 0.138 & 0.242 & 0.053 & 30.76 & 52.13 \\
\hline Beer and Liquor & 20 & 6,406 & 0.014 & 0.421 & 0.076 & 0.229 & 0.065 & 0.81 & 2.27 \\
\hline Wholesale & 302 & 1,205 & 0.014 & 0.641 & 0.134 & 0.217 & 0.057 & 10.66 & 17.01 \\
\hline Products, Machinery & 341 & 731 & 0.013 & 0.570 & 0.112 & 0.200 & 0.062 & 6.91 & 14.33 \\
\hline Others & 175 & 1,330 & 0.012 & 0.599 & 0.093 & 0.153 & 0.075 & 21.21 & 41.38 \\
\hline Steel Works & 242 & 1,179 & 0.011 & 0.721 & 0.103 & 0.141 & 0.039 & 38.55 & 51.79 \\
\hline Printing and Publishing & 155 & 1,224 & 0.011 & 0.562 & 0.076 & 0.138 & 0.050 & 3.58 & 7.07 \\
\hline Automobiles and Trucks & 205 & 1,537 & 0.011 & 0.605 & 0.086 & 0.137 & 0.079 & 5.22 & 9.50 \\
\hline Electrical Equipment & 96 & 1,058 & 0.011 & 0.464 & 0.055 & 0.125 & 0.066 & 6.80 & 15.10 \\
\hline Financials & 1177 & 11,277 & 0.010 & 0.651 & 0.077 & 0.122 & 0.068 & 19.84 & 33.55 \\
\hline Aircrafts, Ships, Railroads & 62 & 3,677 & 0.009 & 0.640 & 0.059 & 0.091 & 0.050 & 10.38 & 18.62 \\
\hline Food Products & 214 & 2,276 & 0.009 & 0.548 & 0.044 & 0.091 & 0.081 & 22.83 & 62.97 \\
\hline Chemicals & 276 & 1,477 & 0.008 & 0.547 & 0.039 & 0.067 & 0.070 & 5.44 & 12.57 \\
\hline Business Supplies & 237 & 2,090 & 0.007 & 0.662 & 0.039 & 0.061 & 0.061 & 4.07 & 6.95 \\
\hline Petroleum, Natural Gas & 379 & 1,972 & 0.007 & 0.616 & 0.035 & 0.057 & 0.066 & 2.18 & 3.64 \\
\hline Mining & 97 & 769 & 0.005 & 0.572 & 0.016 & 0.030 & 0.062 & 0.15 & 0.28 \\
\hline Communication & 204 & 9,146 & 0.005 & 0.623 & 0.015 & 0.025 & 0.095 & 12.29 & 23.68 \\
\hline Tobacco Products & 16 & 26,426 & 0.003 & 0.424 & 0.005 & 0.015 & 0.113 & 0.01 & 0.05 \\
\hline Utilities & 449 & 4,058 & 0.003 & 0.829 & 0.007 & 0.008 & 0.022 & 0.64 & 0.78 \\
\hline Industry Averages & 295 & 3,006 & 0.013 & 0.576 & 0.120 & 0.231 & 0.068 & 13.23 & 24.60 \\
\hline
\end{tabular}




\section{Table 5}

\section{Pearson/Spearman Correlation Matrix}

Correlation matrix of ownership share of the CEO $\left(\delta^{*}\right)$, Book Assets $\left(I^{*}\right)$, Sales, Leverage, R\&D, Advertising, Actual Tobin's $Q$, and Modeled Tobin's $Q^{*}$ values generated from calibrations of the model developed in Sections 2, 3 , and 4. Pearson correlations are below the diagonal and Spearman rank-correlations are above the diagonal. R\&D and advertising are scaled by book value of assets. Data come from the Execucomp and Compustat databases and consist of 8570 firm-year observations from 1993 to 2000. P-values of statistical significance are reported in smaller fond underneath each correlation coefficient.

\begin{tabular}{|c|c|c|c|c|c|c|c|c|c|c|}
\hline & $\delta^{*}$ & $I^{*}$ & Sales & $\begin{array}{l}\text { Debt } \\
\text { Ratio }\end{array}$ & $R \& D$ & $\begin{array}{l}\text { Adver- } \\
\text { tising }\end{array}$ & Act. $Q$ & Mod. $Q^{*}$ & $y$ & $z$ \\
\hline \multirow{2}{*}{$\begin{array}{l}\text { Ownership } \\
\left(\delta^{*}\right)\end{array}$} & 1 & -0.408 & 0.406 & 0.067 & 0.020 & 0.006 & -0.060 & -0.475 & -0.504 & 0.995 \\
\hline & & 0 & 0 & 0 & 0.059 & 0.590 & 0 & 0 & 0 & 0 \\
\hline \multirow[t]{2}{*}{ Assets $\left(I^{*}\right)$} & -0.108 & 1 & -1.000 & -0.457 & -0.123 & -0.428 & 0.321 & 0.651 & 0.746 & -0.485 \\
\hline & 0 & & 0 & 0 & 0 & 0 & 0 & 0 & 0 & 0 \\
\hline \multirow[t]{2}{*}{ Sales } & -0.130 & 0.578 & 1 & 0.458 & 0.123 & 0.428 & -0.321 & -0.650 & -0.745 & 0.483 \\
\hline & 0 & 0 & & 0 & 0 & 0 & 0 & 0 & 0 & 0 \\
\hline \multirow{2}{*}{ Debt Ratio } & -0.022 & -0.036 & 0.010 & 1 & 0.154 & 0.401 & -0.276 & -0.160 & -0.292 & 0.108 \\
\hline & -0.044 & -0.001 & -0.339 & & 0 & 0 & 0 & 0 & 0 & 0 \\
\hline \multirow{2}{*}{$\mathrm{R} \& \mathrm{D}$} & 0.011 & -0.080 & -0.062 & -0.213 & 1 & 0.063 & -0.031 & 0.080 & -0.038 & 0.027 \\
\hline & -0.298 & 0 & 0 & 0 & & 0 & 0.004 & 0 & 0.001 & 0.012 \\
\hline \multirow{2}{*}{ Advertising } & 0.039 & -0.044 & 0.020 & -0.043 & -0.007 & 1 & -0.268 & -0.162 & -0.244 & 0.051 \\
\hline & 0 & 0 & -0.061 & 0 & -0.543 & & 0 & 0 & 0 & 0 \\
\hline \multirow{2}{*}{ Actual $Q$} & 0.068 & -0.086 & -0.037 & -0.218 & 0.331 & 0.067 & 1 & 0.194 & 0.193 & -0.094 \\
\hline & 0 & 0 & -0.001 & 0 & 0 & 0 & & 0 & 0 & 0 \\
\hline \multirow[t]{2}{*}{ Modeled $Q^{*}$} & 0.204 & -0.172 & -0.197 & -0.259 & 0.585 & 0.040 & 0.342 & 1 & 0.859 & -0.520 \\
\hline & 0 & 0 & 0 & 0 & 0 & 0 & 0 & & 0 & 0 \\
\hline \multirow{2}{*}{$y(x=0.5)$} & -0.243 & 0.260 & 0.273 & 0.284 & -0.469 & -0.086 & -0.357 & -0.855 & 1 & -0.555 \\
\hline & 0 & 0 & 0 & 0 & 0 & 0 & 0 & 0 & & 0 \\
\hline \multirow{2}{*}{$z(x=0.5)$} & 0.795 & -0.038 & -0.043 & 0.034 & -0.046 & 0.015 & -0.005 & 0.013 & -0.035 & 1 \\
\hline & 0 & 0 & 0 & -0.002 & 0 & -0.160 & -0.617 & -0.222 & -0.001 & \\
\hline
\end{tabular}


Coles, Jeffrey L., Lemmon, Michael L. and Meschke, Felix, Structural Models and Endogeneity in Corporate Finance: The Link

\section{Table 6}

\section{Pooled OLS Regressions of Actual $Q$ and Modeled $Q *$}

Pooled OLS regression of actual $Q$ and modeled $Q^{*}$ on the ownership share of the CEO $(\delta)$ and the squared ownership share of the CEO $\left(\delta^{2}\right)$. Data come from the Execucomp and Compustat databases and consist of 8570 firm-year observations from 1993 to 2000. Robust $t$-statistics (Rogers, 1993) appear in brackets. Parentheses contain $t$-statistics based on bootstrapped standard errors. Our bootstrap implements the approach outlined on www.kellogg.northwestern.edu/faculty/petersen/htm/papers/se/se programming.htm, by Mitchell Petersen, accessed April 6, 2011. We resample 10,000 times and cluster by company. Asterisks *,**, and *** indicate levels of significance of $10 \%, 5 \%$, and $1 \%$, respectively.

\section{Actual $Q$}

Intercept

$\delta=\delta^{*}$

$\delta^{2}=(\delta *)^{2}$

Observations

Adjusted $\mathrm{R}^{2}$
Model 1

Modeled $Q$ *

$(x=0.5)$

Model 2

$1.9123 * * *$

$8.5872^{* * *}$

$-21.4160^{* * *}$

[-5.68]

$(-5.58)$

8,570

0.0113
$1.7489 * * *$

[97.96]

(96.42)

$8.5647 * * *$

[9.49]

(9.34)

$-20.2063^{* * *}$

[-7.65]

$(-7.41)$

8,570

0.0856
Modeled $Q^{*}$

$(x=0.75)$

Model 3

$1.7537 * * *$

[96.41]

(95.77)

$7.9916^{* * *}$

[8.67]

(8.66)

$-15.5977^{* * *}$

[-5.53]

$(-5.39)$

8,570

0.0916 
Coles, Jeffrey L., Lemmon, Michael L. and Meschke, Felix, Structural Models and Endogeneity in Corporate Finance: The Link

\section{Table 7}

\section{Productivity Parameters and Endogenous Variables by Ownership Decile}

This table groups firms in CEO effective ownership deciles and reports the median values of optimal investment $\left(I^{*}\right.$, in million dollars), effort $\left(g^{*}\right)$, effective CEO ownership $\left(\delta^{*}\right)$, model-generated $Q^{*}$, as well as the solved productivity parameters, $z$ and $y$, for every decile. Data come from the Execucomp and Compustat databases and consist of 8570 firm-year observations from 1993 to 2000. Solution of the model is described in Sections 2, 3, and 4.

\begin{tabular}{rlrllll}
$\boldsymbol{\delta}^{*}$ Decile & $\boldsymbol{\delta}^{*}$ & \multicolumn{1}{c}{$\boldsymbol{I}^{*}$} & $\boldsymbol{g}^{*}$ & $\boldsymbol{Q}$ & $\boldsymbol{y}$ \\
\hline small $=1$ & 0.00134 & 11786 & 0.000000 & 1.47094 & 0.67957 & 0.0000001 \\
2 & 0.00314 & 5110 & 0.000020 & 1.53114 & 0.65382 & 0.0000007 \\
3 & 0.00529 & 3884 & 0.000060 & 1.60595 & 0.62214 & 0.0000018 \\
4 & 0.00772 & 2023 & 0.000110 & 1.65600 & 0.60318 & 0.0000039 \\
5 & 0.01117 & 1298 & 0.000210 & 1.69203 & 0.59231 & 0.0000078 \\
6 & 0.01555 & 909 & 0.000410 & 1.80519 & 0.55415 & 0.0000147 \\
7 & 0.02235 & 678 & 0.000770 & 1.92111 & 0.51942 & 0.0000276 \\
8 & 0.03315 & 529 & 0.002290 & 2.00330 & 0.49805 & 0.0000609 \\
9 & 0.05479 & 423 & 0.008710 & 2.03075 & 0.49612 & 0.0001597 \\
large $=10$ & 0.13673 & 540 & 0.219830 & 1.94933 & 0.51431 & 0.0011648 \\
\hline
\end{tabular}


Coles, Jeffrey L., Lemmon, Michael L. and Meschke, Felix, Structural Models and Endogeneity in Corporate Finance: The Link

\section{Table 8 \\ Pooled OLS Regression of Tobin's $Q$ on CEO Ownership and Control Variables}

Misspecified pooled OLS regression of actual $Q$ and modeled $Q^{*}(x=0.5)$ on CEO ownership and control variables. Data come from the Execucomp and Compustat databases and consist of 8570 firm-year observations from 1993 to 2000. Models 1 and 3 regress modeled $Q^{*}$ and actual $Q$ on the ownership share of the CEO $(\delta)$ and the squared ownership share of the CEO and include the natural logarithm of assets and its squared value as control variables. Models 2 and 4 use the natural logarithm of sales and its squared value as control variables instead, and Model 5 adds the leverage ratio, research and development (R\&D), and advertising expenditures (both scaled by book value of assets). To control for industry effects, Model 5 also includes unreported dummy variables for the 30 FamaFrench industries. Robust $t$-statistics (Rogers, 1993) appear in brackets. Asterisks *, **, and *** indicate levels of significance of $10 \%, 5 \%$, and $1 \%$, respectively.

\begin{tabular}{|c|c|c|c|c|c|}
\hline & \multicolumn{2}{|c|}{ Modeled $Q^{*}$} & \multicolumn{3}{|c|}{ Actual $Q$} \\
\hline & Model 1 & Model 2 & Model 3 & Model 4 & Model 5 \\
\hline \multirow{2}{*}{ Intercept } & $8.2266 * * *$ & $6.3145 * * *$ & $6.6495^{* * *}$ & $6.5478 * * *$ & $3.4399 * * *$ \\
\hline & {$[16.70]$} & [18.29] & [8.87] & [7.60] & [5.32] \\
\hline \multirow{2}{*}{$\delta=\delta^{*}$} & 0.5937 & $2.7158 * * *$ & 1.6140 & $4.0137 * * *$ & $3.1927 * *$ \\
\hline & {$[1.25]$} & {$[5.14]$} & {$[1.07]$} & {$[2.70]$} & {$[2.35]$} \\
\hline \multirow{2}{*}{$\delta^{2}=(\delta *)^{2}$} & -1.4008 & $-6.0487 * * *$ & -4.9993 & $-10.2603 * * *$ & $-7.0001 * *$ \\
\hline & {$[-1.05]$} & {$[-3.75]$} & {$[-1.40]$} & {$[-2.85]$} & {$[-2.17]$} \\
\hline \multirow{2}{*}{$\ln$ (Assets) } & $-1.4507 * * *$ & & $-1.0052 * * *$ & & \\
\hline & {$[-11.57]$} & & {$[-5.47]$} & & \\
\hline \multirow{2}{*}{$\ln (\text { Assets })^{2}$} & $0.0767 * * *$ & & $0.0494 * * *$ & & \\
\hline & {$[10.03]$} & & {$[4.52]$} & & \\
\hline \multirow[t]{2}{*}{$\ln$ (Sales) } & & $-1.0353 * * *$ & & $-1.1324 * * *$ & -0.2700 \\
\hline & & {$[-11.04]$} & & {$[-4.80]$} & {$[-1.56]$} \\
\hline \multirow[t]{2}{*}{$\ln (\text { Sales })^{2}$} & & $0.0550 * * *$ & & $0.0661 * * *$ & 0.0158 \\
\hline & & {$[8.95]$} & & {$[4.21]$} & [1.38] \\
\hline \multirow{2}{*}{ Leverage } & & & & & $-1.8850 * * *$ \\
\hline & & & & & {$[-9.55]$} \\
\hline \multirow[t]{2}{*}{ R\&D/Assets } & & & & & $4.1653 * * *$ \\
\hline & & & & & [3.14] \\
\hline \multirow[t]{2}{*}{ Advertising/Assets } & & & & & $2.5909 * * *$ \\
\hline & & & & & [2.76] \\
\hline Industry Dummies & no & no & no & no & yes \\
\hline Observations & 8,570 & 8,570 & 8,570 & 8,570 & 8,570 \\
\hline Adjusted $\mathrm{R}^{2}$ & 0.5601 & 0.4799 & 0.0568 & 0.0574 & 0.1986 \\
\hline
\end{tabular}


Coles, Jeffrey L., Lemmon, Michael L. and Meschke, Felix, Structural Models and Endogeneity in Corporate Finance: The Link

\section{Table 9}

\section{Nonlinear Regression of Tobin's $Q$ on Ownership and Productivity Parameters}

Correctly specified nonlinear OLS regression of actual $Q$ and modeled $\mathrm{Q}^{*}$ on the ownership share of the CEO $(\delta)$, squared ownership share of the CEO $\left(\delta^{2}\right)$, model-generated expected $E Q^{*}$, and control variables. Data come from the Execucomp and Compustat databases and consist of 8570 firm-year observations from 1993 to 2000. Robust $t$ statistics (Rogers, 1993) appear in brackets. Asterisks *, **, and *** indicate levels of significance of $10 \%, 5 \%$, and $1 \%$, respectively.

\begin{tabular}{|c|c|c|c|c|}
\hline & & & & \\
\hline & Model 1 & Model 2 & Model 3 & Model 4 \\
\hline Intercept & -0.0304 & 0.0000 & $6.9524 * * *$ & 0.3257 \\
\hline & {$[-0.69]$} & {$[0.00]$} & [3.17] & [1.33] \\
\hline$\delta=\delta^{*}$ & 0.0133 & $-0.0000 * * *$ & -1.4900 & 0.8173 \\
\hline & [1.26] & {$[-8.49]$} & {$[-0.99]$} & {$[0.58]$} \\
\hline$\delta^{2}=(\delta *)^{2}$ & 0.0752 & $0.0000 * * *$ & 1.8210 & -3.0847 \\
\hline & {$[0.90]$} & {$[6.71]$} & {$[0.20]$} & {$[-0.92]$} \\
\hline$y$ & 0.0613 & & $-12.6489 * * *$ & \\
\hline & {$[0.66]$} & & {$[-2.85]$} & \\
\hline$z$ & $-2.5451 * *$ & & 27.6833 & \\
\hline & {$[-2.17]$} & & {$[0.27]$} & \\
\hline$y^{2}$ & -0.0389 & & $6.8359 * *$ & \\
\hline & {$[-0.64]$} & & {$[2.41]$} & \\
\hline$z^{2}$ & 14.0236 & & $-1,106.6865$ & \\
\hline & {$[0.80]$} & & {$[-0.80]$} & \\
\hline $1 / y$ & $1.0046 * * *$ & & -0.0008 & \\
\hline & [159.22] & & {$[-0.00]$} & \\
\hline $1 / z$ & $0.0000^{*}$ & & 0.0000 & \\
\hline & {$[1.94]$} & & {$[1.46]$} & \\
\hline$E Q^{*}$ & & $1.0000^{* * *}$ & & $0.9072 * * *$ \\
\hline & & {$\left[6.12 \times 10^{17}\right]$} & & [6.57] \\
\hline Observations & 8,570 & 8,570 & 8,570 & 8,570 \\
\hline Adjusted $\mathrm{R}^{2}$ & 0.9996 & 1.0000 & 0.1354 & 0.1168 \\
\hline
\end{tabular}


Coles, Jeffrey L., Lemmon, Michael L. and Meschke, Felix, Structural Models and Endogeneity in Corporate Finance: The Link

\section{Table 10}

\section{Fixed Effects Regression of Tobin's $Q$ on Ownership and Control Variables}

Misspecified firm fixed effects regression of actual $Q$ and modeled $Q^{*}(x=0.5)$ on CEO ownership $(\delta)$ and control variables. Data come from the Execucomp and Compustat databases. Models 1 and 4 regress modeled $Q^{*}$ and actual $Q$ on the ownership share of the CEO and the squared ownership share of the CEO. Models 2 and 5 add the natural logarithm of sales and its squared value, leverage, research and development (R\&D), and advertising expenditures (both normalized by book value of assets). Models 3 and 6 add the structural parameters, $z$ and $y$, which are generated from solution of the model as described in Sections 2 - 4. Robust $t$-statistics (Rogers, 1993) appear in brackets. Asterisks *, $* *$, and $* * *$ indicate levels of significance of $10 \%, 5 \%$, and $1 \%$, respectively.

\begin{tabular}{|c|c|c|c|c|c|c|}
\hline & \multicolumn{3}{|c|}{ Modeled $Q^{*}$} & \multicolumn{3}{|c|}{ Actual $Q$} \\
\hline & Model 1 & Model 2 & Model 3 & Model 4 & Model 5 & Model 6 \\
\hline \multirow{2}{*}{ Intercept } & $1.8534 * * *$ & $3.8142 * * *$ & $6.2290 * * *$ & $2.0547 * * *$ & 1.5979 & $2.7166^{* *}$ \\
\hline & [62.24] & [5.81] & [14.51] & [41.07] & {$[1.41]$} & {$[2.50]$} \\
\hline \multirow[t]{2}{*}{$\delta=\delta^{*}$} & $3.4337 * * *$ & $1.7889 * *$ & -0.1750 & 2.0658 & 3.2467 & 1.5112 \\
\hline & [3.05] & {$[2.41]$} & {$[-0.31]$} & {$[0.99]$} & {$[1.60]$} & {$[0.72]$} \\
\hline \multirow{2}{*}{$\delta^{2}=(\delta *)^{2}$} & $-5.2767 * *$ & $-2.9616^{* *}$ & 10.2368 & -4.6924 & -6.8143 & -2.2407 \\
\hline & {$[-2.50]$} & [-1.99] & {$[1.23]$} & {$[-1.01]$} & {$[-1.47]$} & {$[-0.25]$} \\
\hline \multirow{2}{*}{$\ln ($ Sales $)$} & & $-0.3808^{* *}$ & & & -0.0561 & \\
\hline & & {$[-2.14]$} & & & {$[-0.19]$} & \\
\hline \multirow[t]{2}{*}{$\ln (\text { Sales })^{2}$} & & 0.0135 & & & 0.0220 & \\
\hline & & [1.16] & & & {$[1.09]$} & \\
\hline \multirow[t]{2}{*}{ Leverage } & & $-0.2262 * * *$ & & & $-2.0077^{* * *}$ & \\
\hline & & {$[-4.20]$} & & & {$[-5.35]$} & \\
\hline \multirow{2}{*}{$\mathrm{R} \& \mathrm{D} /$ Assets } & & $3.5784 * * *$ & & & 1.0701 & \\
\hline & & [4.69] & & & {$[0.80]$} & \\
\hline \multirow{2}{*}{ Advertising/Assets } & & 0.0372 & & & -0.0369 & \\
\hline & & {$[0.20]$} & & & {$[-0.04]$} & \\
\hline \multirow[t]{2}{*}{$y$} & & & $-7.6455 * * *$ & & & -1.1564 \\
\hline & & & {$[-9.85]$} & & & {$[-0.60]$} \\
\hline \multirow{2}{*}{$z$} & & & -98.8327 & & & -15.8806 \\
\hline & & & {$[-1.30]$} & & & {$[-0.27]$} \\
\hline \multirow{2}{*}{$\begin{array}{l}\text { Observations } \\
\text { Adjusted } \mathrm{R}^{2}\end{array}$} & 8,570 & 8,570 & 8,570 & 8,570 & 8,570 & 8,570 \\
\hline & 0.8678 & 0.9161 & 0.9178 & 0.6835 & 0.6908 & 0.6835 \\
\hline
\end{tabular}




\section{Table 11}

\section{Two-Stage Least-Squares Regressions of CEO Ownership and Tobin's $Q$}

Two-Stage Least-Squares Regressions of CEO ownership and modeled $Q^{*}(x=0.5)$ and control variables. Data come from the Execucomp and Compustat databases and consist of 8570 firm-year observations from 1993 to 2000. Model 1 displays an OLS regression on CEO effective ownership $\left(\delta=\delta^{*}\right)$, while Models 2-4 show an OLS regression and two instrumental variable regressions on modeled $Q^{*}$. Robust $t$-statistics (Rogers, 1993) appear in brackets. Asterisks *, **, and $* * *$ indicate levels of significance of $1 \%, 5 \%$, and $10 \%$, respectively.

\begin{tabular}{|c|c|c|c|c|}
\hline & Ownership $\delta=\delta^{*}$ & & deled $Q^{*}$ & \\
\hline & Model 1 & Model 2 & Model 3 & Model 4 \\
\hline Intercept & $0.0209 * * *$ & $1.9402 * * *$ & $1.8707 * * *$ & -0.0303 \\
\hline & {$[28.96]$} & {$[111.60]$} & [85.55] & {$[-0.68]$} \\
\hline$z$ & $46.2449 * * *$ & $35.8796^{* * *}$ & & \\
\hline & [12.56] & {$[2.58]$} & & \\
\hline$z^{2}$ & $-919.6214 * * *$ & $-1,363.8842 * * *$ & & \\
\hline & {$[-4.56]$} & {$[-2.63]$} & & \\
\hline $1 / z$ & $-0.0000 * *$ & $-0.0000 * * *$ & & \\
\hline & {$[-2.45]$} & {$[-2.69]$} & & \\
\hline Fitted $\delta=\delta^{*}$ & & & $3.2750 * * *$ & $0.0670 * * *$ \\
\hline & & & {$[5.10]$} & [2.84] \\
\hline Fitted $\delta^{2}=(\delta *)^{2}$ & & & $-8.0999 * * *$ & $-0.2939 * * *$ \\
\hline & & & {$[-5.25]$} & {$[-4.34]$} \\
\hline$y$ & & & & 0.0555 \\
\hline & & & & {$[0.59]$} \\
\hline$y^{2}$ & & & & -0.0324 \\
\hline & & & & {$[-0.53]$} \\
\hline $1 / y$ & & & & $1.0046 * * *$ \\
\hline & & & & {$[157.90]$} \\
\hline Observations & 8,570 & 8,570 & 8,570 & 8,570 \\
\hline Adjusted R-squared & 0.7903 & 0.0054 & 0.0518 & 0.9996 \\
\hline
\end{tabular}




\section{Figure 1}

Plots of Predicted Tobin's $Q$ or $Q^{*}$ on $\delta=\delta^{*}$

\section{Based on Regression of Actual $Q$ and of Model-generated $Q^{*}$ (for Various Parameter Values) on Effective CEO Ownership}

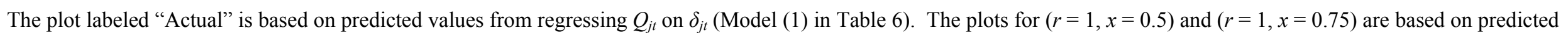

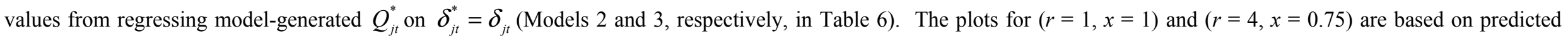
values from unreported regressions of model-generated $Q_{j t}^{*}$ on $\delta_{j t}^{*}=\delta_{j t}$.

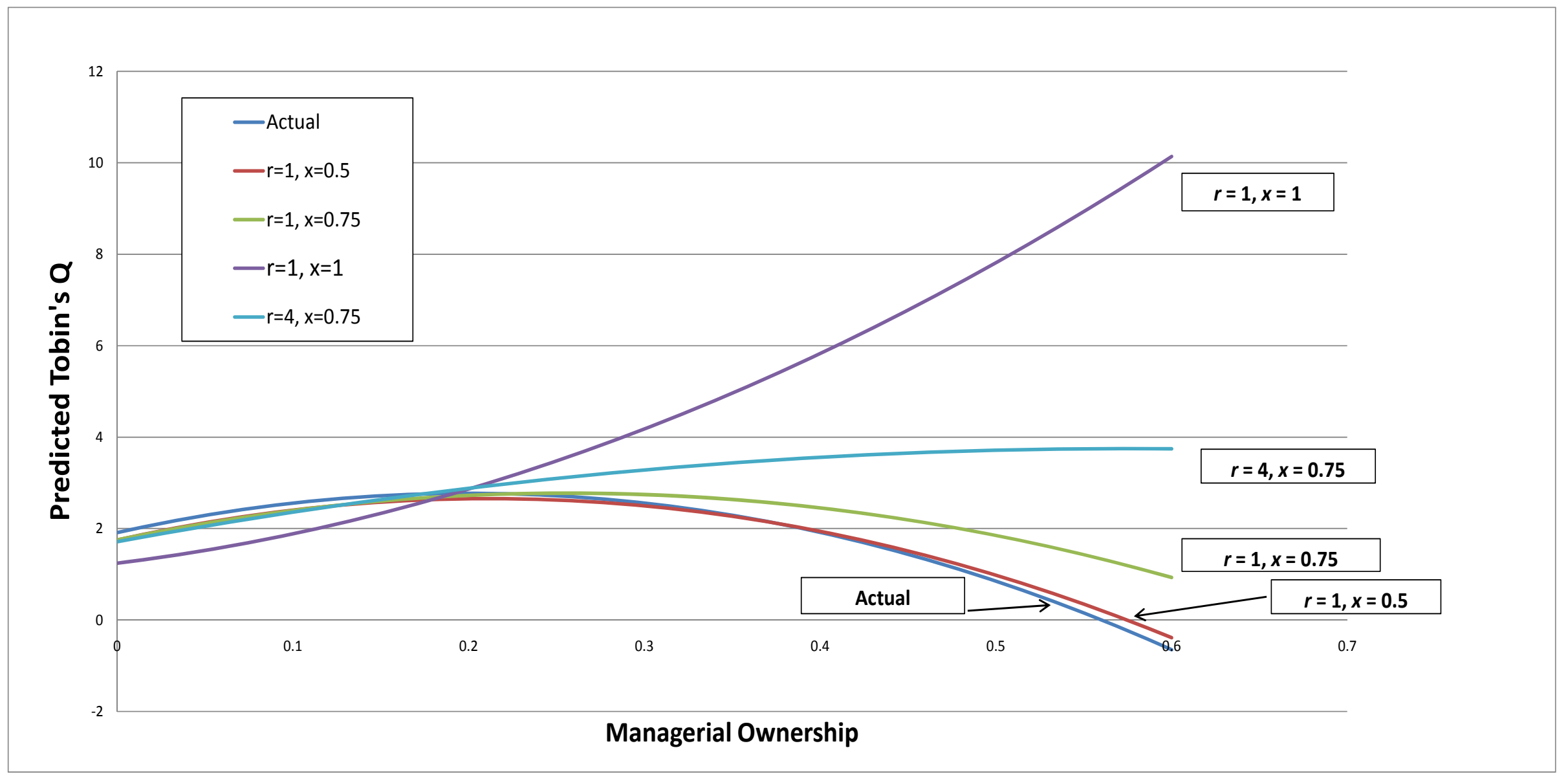

